\title{
Program NetMoment;
} Simultaneous Calculation of Moment, Source Corner Frequency, and Site Specific $t^{*}$ from Network Recordings

\author{
L. Hutchings
}

December 12, 2001

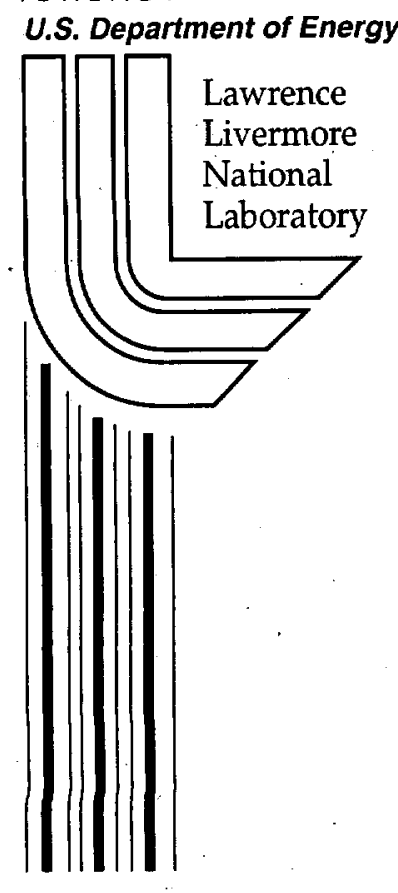




\section{DISCLAIMER}

This document was prepared as an account of work sponsored by an agency of the United States Government. Neither the United States Government nor the University of California nor any of their employees, makes any warranty, express or implied, or assumes any legal liability or responsibility for the accuracy, completeness, or usefulness of any information, apparatus, product, or process disclosed, or represents that its use would not infringe privately owned rights. Reference herein to any specific commercial product, process, or service by trade name, trademark, manufacturer, or otherwise, does not necessarily constitute or imply its endorsement, recommendation, or favoring by the United States Government or the University of California. The views and opinions of authors expressed herein do not necessarily state or reflect those of the United States Government or the University of California, and shall not be used for advertising or product endorsement purposes.

This work was performed under the auspices of the U.S. Department of Energy by the University of California, Lawrence Livermore National Laboratory under Contract No. W-7405-Eng-48.

This report has been reproduced directly from the best available copy.

Available electronically at http://www.doe.gov/bridge

Available for a processing fee to U.S. Department of Energy

and its contractors in paper from

U.S. Department of Energy

Office of Scientific and Technical Information

P.O. Box 62

Oak Ridge, TN 37831-0062

Telephone: (865) 576-8401

Facsimile: (865) 576-5728

E-mail: reports@adonis.osti.gov

Available for the sale to the public from

U.S. Department of Commerce

National Technical Information Service

5285 Port Royal Road

Springfield, VA 22161

Telephone: (800) 553-6847

Facsimile: (703) 605-6900

E-mail: orders@ntis.fedworld.gov

Online ordering: http://www.ntis.gov/ordering.htm

OR

Lawrence Livermore National Laboratory

Technical Information Department's Digital Library

http://www.llnl.gov/tid/Library.html 
Program NetMoment; Simultaneous Calculation of Moment, Source Corner Frequency, and Site Specific $t *$ from Network Recordings

\author{
Lawrence Hutchings \\ Lawrence Livermore National Laboratory \\ Hazard Mitigation Center \\ P.O. Box 808 \\ Livermore, California 94551
}

UC/LLNL Campus/Laboratory Collaboration Project

December 12, 2001 


\section{Introduction}

The purpose of computer program NetMoment (Appendix I) is to utilize fundamental knowledge of earthquake sources, propagation attenuation, and site response in a simultaneous inversion of network data to determine the moment and source corner frequency of earthquakes, and site specific $t^{*}$. The source parameters are especially difficult to determine for small earthquakes.

A fundamental problem in determining the source corner frequencies of small earthquakes is that site response can result in spectral corner frequencies in the range that may be expected from the earthquakes themselves. Several authors have identified this as fmax (Hanks, 1982), a constant corner frequency for small events so that below a threshold moment (about 1.0 $\times 10^{21}$ dyne- $\mathrm{cm}$ ) the corner frequency remains constant as the size of events diminishes. Hutchings and $\mathrm{Wu}(1990)$ found that for the southern California region, events with moment less than about $1.5 \times 10^{21}$ dyne-cm (about magnitude 3.4) show no source effect in their spectra. Hanks (1982) found the threshold to be about $1.0 \times 10^{21}$ dyne-cm for other southern California sites. Baise et al. (2002) found borehole recordings on Yerba Buena Island, in San Francisco Bay, to have corner frequencies limited to about $3-5 \mathrm{~Hz}$ for $\mathrm{M}<4.0$ earthquakes in the region. Some authors have attributed this to a minimum source dimension for earthquakes, which results in a decrease in stress drop for smaller events (Archuleta et al., 1982; Papageorgiou and Aki, 1983). An alternative explanation is that the constant corner frequencies result from whole path or near site attenuation and/or amplifications due to soil response. This is supported by a wide body of literature (Anderson and Hough, 1984, Hutchings and Wu, 1990, Blakeslee and Malin, 1991; Aster and Shearer, 1991; Abercrombie, 1995). Abercrombie, for example, estimated source corner frequencies from events recorded in granite at a depth of $2.5 \mathrm{Km}$ in the Cajon Pass scientific drill hole and observed corner frequencies about a factor of 10 higher than observed at the surface.

An interesting question regarding fmax is that if there is a spectral fall-off due to attenuation and an apparent source corner frequency in the spectra, then there should be an additional fall-off at frequencies above the actual source corner frequency (Jarpe et al., 1989). A Brune source model with 100 bar stress drop predicts a source corner frequency of $6.0 \mathrm{~Hz}$ and $15 \mathrm{~Hz}$ for events with moment of $1.0 \times 10^{21}$ and $1.0 \times 10^{20}$ dyne-cm, respectively (about magnitude 3.2 and 2.2, respectively). If source corner frequencies are not observed, then this suggests that stress drops are higher than 100 bars. Wennerberg has attempted spectral division with empirical Green's functions to try to identify the actual source corner frequency of larger events and was not able to (Wennerberg, 1983). One aspect of program NetMoment is that it attempts to find both the spectral fall-off due to attenuation and the source spectral shape (source corner frequency) in observed spectra.

Knowing the corner frequency of source events for empirical Green's functions is important when synthesizing ground motion because most empirical Green's function approaches assume that corner frequencies of source events are known. Hutchings and $\mathrm{Wu}(1990)$ assume that source events are small enough that the events are effectively 
impulsive point sources, so that their corner frequencies should be higher than the highest frequency to be modeled. If source events have corner frequencies that are known, then a source model (i.e. Brune source) can be used to deconvolve out a source spectral shape from the EGF's to create effective impulsive point source events.

The moment of small events is also difficult to determine because records are usually band limited by cultural noise to about $0.5 \mathrm{~Hz}$, and at this frequency range the site response and near surface propagation path $Q$ effects on spectra can be significant. However, knowing the moment of local earthquakes provides a valuable comparison of relative earthquake size, and is essential to estimate stress drop. Also, knowing the moment of source events used in strong ground motion synthesis with empirical Green's functions is critical to the predictive capability for strong ground motion because amplitudes of synthesized accelerograms are linearly dependent upon their moment estimate. Approaches such as Irikura (1994), Hutchings and Wu (1990) and most other approaches (see Joyner and Boore, 1982), add up or scale empirical Green's functions based upon the moment estimate of the small events.

If moments are calculated from long period spectral levels that are affected by site response, then inaccurate values will be estimated. Kasameyer and Jarpe (1996) and Bonilla et al. (1997) showed that site response is significant for frequencies at least to $0.5 \mathrm{~Hz}$ for soil sites. However, usually the moment that is calculated is one that is an average of all moments estimated. This can be dealt with by weighting the moment estimates, so that hard rock sites that are less likely to be affected by site response are given more weight when determining moments. However, the bias introduced by site response when determining moments of small earthquakes needs more research.

\section{Theory}

The joint inversion is based upon the assumption that corrected long period spectral levels and the source corner frequencies from a particular earthquake will have the same value at each site, so that differences in spectra are due to propagation path and individual site $t^{*} . t^{*}$ is $R /(Q V)$ and is raised to the negative power of the exponent to model attenuation as $\exp \left(-\pi f t^{*}\right) . R$ is distance traveled, $V$ is velocity, and $Q$ is the seismic quality factor. We corrected spectra for whole path $t_{r}^{*}$ and solved for site specific $t_{g}^{*}$. Anderson and Hough (1984) showed that to a first approximation attenuation could be separated into a near-surface attenuation and an attenuation at death. Our assumption is that whole path attenuation is fairly uniform and determined from the velocity model. We also assume that $V Q$ near a site will vary with individual site conditions. It is well known, for example, that poorly consolidated materials have low velocities and low $Q$ values, and thus would have high $t_{g}^{*}$ values. Similarly, rock has high velocity and high $Q$ values and would have low $t_{g}^{*}$ values. Of course, we cannot identify what is specifically contributing to $t_{g}^{*}$ and over what distance range. In particular, there is a trade-off 
between $t_{r}^{*}$ and $t_{g}^{*}$. Here, we use $t_{r}^{*}$ to normalize for propagation distance and examine relative values of $t_{g}^{*}$. We assume that to a first order $\mathrm{Q}$ and thus $t^{*}$ is frequency independent. This is supported by observations to calculate $Q$ in the shallow crust (Hough et al., 1988; Frankel and Wennerberg, 1989).

We used a nonlinear least squares best fit of displacement spectra of the S-wave energy of the recorded seismograms to the Brune source model to solve for our free parameters. The Fourier amplitude spectra of recorded seismograms were corrected to represent moment at the long period asymptote and for whole path attenuation. They were then fit to the Brune (1972) displacement spectral shape with site specific $t^{*}$ and moment as the long period spectral asymptote. Spectra were fit to the modified Brune spectra:

$$
\Omega(f)=\frac{M_{o} \exp \left(-\pi f t_{g}^{*}\right)}{\left[1+\left(\frac{f}{f_{c}}\right)^{2}\right]}
$$

where $M_{o}$ is the moment, $f$ is frequency, $f_{c}$ is the source corner frequency, and $t_{g}^{*}$ is site specific $t^{*}$. The best fitting combination of free permeates $\left(M_{o}, f_{c}, t_{g}^{*}\right)$ was found by iteration from a starting model using the Simplex algorithm (Cacceci and Cacheris, 1984; Nelder and Mead, 1965; Numerical Recipes, 1998, Chapter 10.4).

The correction to spectra prior to the joint inversion is based upon the equation for moment from Aki and Richards (1980, pg. 116). Spectra of recorded seismograms were corrected by:

$$
\Omega^{\prime}(f)=\frac{4 \pi R \rho_{x}^{1 / 2} \rho_{\zeta}^{1 / 2} \beta_{x}^{1 / 2} \beta_{\zeta}^{5 / 2}}{s^{s}{ }^{s}} U(f) \exp \left(\pi f t_{r}^{*}\right)
$$

where $U(f)$ is the recorded displacement spectra, $t_{r}^{*}$ is whole path $t^{*}, R$ is correction for geometrical spreading, $\rho_{x}$ is density at the station and $\rho_{\zeta}$ is density at the source, $\beta_{x}$ is shear velocity at the station and $\beta_{\zeta}$ is shear velocity at the source. $S$ and $F$ are the free surface correction and focal mechanism correction, respectively. The free surface correction is determined from the velocity model using the reflection coefficients as outlined in Aki and Richards (1980, pg. 190). The focal mechanism correction is determined by the radiation pattern as outlined by Aki and Richards (1980, pg. $115), \Omega^{\prime}(f \rightarrow 0)=M_{o}$. 


\section{Application to Athens}

The 7 September 1999, Mw=5.9 Athens earthquake is the first moderate-to-strong earthquake ever reported to have occurred at such a small distance $(20 \mathrm{~km})$ from the historical center of the city. Officials reported that about 100 buildings collapsed, which caused 143 casualties. The National Observatory of Athens, Institute of Geodynamics (NOAIG) recorded the main earthquake and aftershocks at several locations in the metropolitan area (Kalogeras and Stavrakakis, 1999), and the University of Athens, Department of Geophysics-Geothermics (UoADGG) recorded aftershocks in many locations where damage was significant (Papadimitriou et al., 2000). Figure 1 shows the morphology of the Athens area, the epicenter of the main shock, and locations of stations used in this study. The results discussed here were previously published in (Ioannidou et al., 2002).

Weak motion recordings were obtained from aftershocks at a wide range of distances from 9 to $52 \mathrm{~km}$. NOAIG data were recorded by their permanent strong motion array and Attico Metro S. A. instruments. The procedure for processing strong motion records of NOAIG is based on the standard procedure of the CALTECH Institute (Trifunac and Lee, 1973), and is described, in detail, by Stavrakakis et al. (1993). The instrument correction used is that described by many investigators (Hudson \& Brady, 1971; Trifunac \& Lee, 1973; Trifunac et al., 1973; Hudson, 1979; Trifunac \& Lee, 1979), while values of Ormsby filters proposed by Basili \& Brady (1978) and used by previous authors for processing strong motion records in Greece (Carydis et al., 1984; Margaris, 1986; Anagnostopoulos et al., 1986; Carydis et al., 1989; Makropoulos et al., 1989; Lekidis et al., 1991), are applied.

The UoADGG deployed two types of stations during the installation of the temporary network. Acceleration was recorded at sites PEFK and COUR, situated within the center of the network, using Kinemetrics ETNA instruments. The previously mentioned procedure for processing strong motion accelerometer records was applied on the data from these stations. At the NEOK, STEF, MAGO, FILI, PSAR and ZOFR sites RefTec recording instruments were installed. The first four of these were equipped with the LE3D $1 \mathrm{~Hz}$ Lennartz sensor while the last two stations were connected to GURALP CMG 40-T broadband seismometers. The records obtained were instrument response corrected according to the sensor specifications to obtained velocity time histories.

Table 3 lists source information for the events used in this study. Hypocentral locations for the main event and many of the aftershocks were obtained from Papadopoulos et al. (2000) (indicated by an * in Table 3). Locations for the events shortly after the main event (indicated by a + in Table 3 ), which were not recorded by temporary local networks, were obtained using information from the permanent networks in Greece and s-p ${ }^{\circ}$ arrival time intervals from the strong ground motion records (Kalogeras and Stavrakakis, 1999). Focal mechanism solutions were obtained from Papadopoulos et al. (2000). In addition, several events were located and focal mechanism solutions were 
obtained by combining data from NOAIG with that from the UoADGG. These are identified by ++ in Table 3. These hypocentral solutions are consistent with other solutions obtained in this study. Since these solutions used a different station distribution, and a slightly varied velocity model, this gives confidence that the locations of events used in this study are near the limit of accuracy that can be achieved for this area. The focal mechanism solutions from the combined data are close to that of the main event, as are many of the events listed in Table 3 from Papadopoulos et al. (2000). Table 4 lists the stations used in the inversion and Figure 9 shows a plot of their locations along with the location of the source event.

\section{Analysis}

The focal mechanism correction is determined by the radiation pattern as outlined by Aki and Richards (1980, pg. 115), and discussed further below. Density is determined from the shear wave velocity by the linear relation: $\rho=(\beta-0.35) / 1.88$ (Lama and Vutukuri, 1978). $\Omega^{\prime}(f \rightarrow 0)=M_{o}$. Ten seconds of $S$ arrivals were used in the calculation. We are using $Q_{S}$ for whole path $t^{*}$ since only S-waves are used in the inversion. Seismograms were rotated to radial and transverse components, and the vertical and radial were square-of-sum-squared added to get one $S v$ spectrum, then the $S v$ and $S h$ components were corrected for focal mechanism solution. $S v$ and $S h$ components were square-ofsum-squared added to get one $S$-wave spectrum and corrected with the remaining corrections of equation 2 before the inversion. Corrected spectra were fit to equation 1 by fitting frequencies from 1.0 to $20.0 \mathrm{~Hz}$ for most aftershocks, and 0.3 to $25.0 \mathrm{~Hz}$ for the main event. Some aftershocks had better signal to noise and were fit to 0.5 to $20.0 \mathrm{~Hz}$, and some had worse signal to noise and were fit to 2.0 to $15.0 \mathrm{~Hz}$. These frequency ranges ensured that all recordings were above noise. Table 3 lists the number of aftershocks at each used in the inversion.

Obviously, model parameters are dependent upon the constants used in the equations 1 and 2. We attempted to identify the uncertainty attributed to these constraints. The moment is dependent upon shear velocity to the $4^{\text {th }}$ power. Shear velocity is to the $3^{\text {rd }}$ power in equation 2 and density is determined from the shear velocity from the linear relation: $\rho=(\beta-0.35) / 1.88$ (Lama and Vutukuri, 1978). In equation 2:

$\rho_{x}=2.37 \mathrm{gm} / \mathrm{cm}^{3}$ is the surface density and is based upon near surface basement rock $P$-wave velocity of $4.1 \mathrm{~km} / \mathrm{sec}$. It is assumed that the long period waves used to calculate moment sample primarily the basement structure. $\rho_{\zeta}$ varies with the depth of the event, $\rho_{\zeta}=3.26 \mathrm{gm} / \mathrm{cm}^{3}$ for the main shock. A difference of $20 \%$ in shear velocity results in a change in moment value of about a factor of 2 .

There is a fairly significant scatter in long period spectral levels of a factor of up to \pm 5 . This may be due to either a difference in site response at low frequencies, an inappropriate correction for focal mechanism solution, directivity effects, hypocentral location, or unidentified long period noise. We excluded significant directivity effects as the 
cause because of the size of aftershocks used, and determined that at frequencies between 1.0 and 20.0 the signal to noise ratio was such that noise was not a cause. We also identified that a similar difference in spectral amplitudes as observed at long period spectral levels was evident throughout the frequency range of recording. This suggests that it is due to inappropriate FMS corrections or systematic amplifications. We examined the effect of focal mechanism solution (FMS) correction for amplitude and found that there was a reduction in the scatter if a FMS correction was applied. If a FMS was available, we applied a correction that was limited to a minimum of 0.25 (see Hutchings and $\mathrm{Wu}, 1990$ ). If a FMS was not available, an average value of 0.63 was used for the FMS radiation pattern correction ( $\mathrm{Wu}$ and Ben-Menahem, 1965). We could not identify whether site response was a contributing factor. We calculated the standard deviation of the moment calculation for all the events together to be a factor of \pm 2.1 .

The fit to $t_{g}^{*}$ and fc are dependent upon the long period spectral level and in a simultaneous inversion this can result in a bias. For example, if a site has a factor of 2 greater long period spectral level than the solution for the joint inversion, and is forced to fit the site specific high frequency, then the $t_{g}^{*}$ value will be higher and the fc will be lower than if spectra were fit individually. Therefore, in an effort to get unbiased value of $t_{g}^{*}$ and fc we normalized spectra to have the same long period spectral level (average of all recordings for a particular event), then conducted the simultaneous inversion. This did not affect the moment calculation significantly because $t_{g}^{*}$ generally has minimal effect at these periods and the spectral fit of the inversion is primarily the mean of long period values anyway. This inherently adds the assumption that at the longest periods, site response is not a factor.

There is an obvious trade-off between the $t_{r}^{*-}$ correction and $t_{g}^{*}$. However, we found essentially no trade-off between source corner frequency and choice of $Q_{S}$ between 250 and 1000 for $t_{r}^{*}$. We have limited the range for whole path $Q_{S}$ of between 250 and 500 from previous studies of $Q_{S}$ and our analysis. Hashida et al. (1988) used macroseismic data and found that an average $Q_{S}$ ranges between 50 and 1000 for the crust for the whole area of Greece and that the Continental Greece is an area of higher $Q_{s}$ in the crust than the Aegean area. Papazachos (1992) by using the same kind of data but in a different approach estimated a mean $Q_{S}$ of $350 \pm 140$ at around $1 \mathrm{~Hz}$ for the same region. Hatzidimitriou et al. (1993) by using acceleration data found $Q_{s}$ values ranging between 30 and 360 for frequencies $4-10 \mathrm{~Hz}$. We found that a $Q_{S}$ value of 350 to 500 for whole path $Q$ correction gave the most consistent spectral fall-off at all stations. In particular, lower values of $Q_{S}$ resulted in an over correction when applied to distant stations, such as THVC and RFNA, and a spectral slope that was lower at higher frequencies. We have used a value of $Q_{S}=350$ for $t_{r}^{*}$ correction. 


\section{Results}

Table 1 lists individual $t_{g}^{*}$ values obtained from program NetMoment, along with one standard deviation values of those sites that had 4 or more recordings. Table 3 lists the moment and corner frequency obtained for the source events. A reliable moment value was not obtained for the main event because the source corner frequency is near the low frequency recording limit of about $0.5 \mathrm{~Hz}$. Figure 4 shows a plot of calculated $t_{g}^{*}$ values at each station. The circle size corresponds to $t_{g}^{*}$ values. Figures 5 and 6 show fits of moment, the Brune source model, and $t_{g}^{*}$ to corrected spectra for twelve of the events. There are several points that should be noted. First, there is one spectral fit for each spectra plotted, and they all converge to a common asymptotic value, the moment. The spectra are shown only for the frequency range where data is considered adequate for the study, and the asymptotic fit to the Brune source model may have a higher value than is indicated by the plot. Since $t^{*}$ is not allowed to be negative, spectra that have a slope less than the $1 / f^{2}$ of the Brune source model cannot be fit. See, for example, the spectra with shallow slope for event 990907115651 , the main event. Spectra such as these will have $t_{g}^{*}$ of zero, and are interpreted to have had no $t_{g}^{*}$. It is recognized that a site specific amplification can have this effect, and thus bias results. Generally, spectra show varying slopes of the high frequency fall-off due to $t_{g}^{*}$.

Figure 7 shows the corner frequency values as a function of moment for the events in this study. Also plotted is the corner frequency relationship predicted by a Brune source model with 100 bar stress drop. It is apparent that corner frequencies identified in this study are consistent with those generally described by the Brune source model. Scatter in corner frequencies may be due to variation in stress drop or uncertainties in corner frequency picks. Trial and error calculations for this study shows that corner frequency picks vary by about $\pm 1 \mathrm{~Hz}$, depending upon choices in calculating the $\mathrm{L} 2$ norm.

\section{References}

Abercrombie, Rachael E. (1995) Earthquake source scaling relationships from -1 to $5 \mathrm{M}_{\mathrm{L}}$ using seismograms recorded at 2.5-km depth. J. Geophys. Res. 10024015 - 24036.

Aki, K. and P. G. Richards (1980). Quantitative seismology, Theory and Methods, Volumes I and II, W. H. Freeman and Company, San Francisco, CA.

Anderson, J.G. and S. Hough (1984) A model for the shape of the Fourier amplitude spectra of accelerograms at high frequencies. Bul. Seis. Soc. Am. 74, 1969-1994.

Archuleta, R., F/ Bonilla, M. Doroudian, F. Heuze, P-C. Liu, and J. Steidl (2000) Strong Earthquake Motion Estimates for the UCSB Campus, and Related Response of the Engineering I Building", UC/CLC report. 
Baise, Laurie, Lawrence Hutchings, and Steven Glaser (2002) Analysis of Site Response at Yerba Buena Island, San Francisco Bay, California from Weak Motion Recordings. submitted to Special Issue on Site Response, Bollettino di Geofisica, Trieste, Italy.

Blakeslee, S. and P. Malin (1991) High-frequency site effects at two Parkfield downhole and surface stations. Bul. Seis. Soc. Am. 81, 332-345.

Bonilla, Luis Fabian, Jamison H. Steidl, Grant T. Lindley, Alexei G. Tumarkin, and Ralph J. Archuleta (1997) Site amplification in the San Fernando valley, CA: variability of the site effect estimation using the S-wave coda, and H/V methods. Bul. Seis. Soc. Am. 87, 710-730.

Brune, J.N. (1971) Tectonic Stress and the Spectra of Seismic Shear Waves from Earthquakes. J. Geophys. Res. 75, 4997-5010 (Correction, J. Geophys. Res. 76(20), 5002, 1972).

Caceci, M.S. and W.P. Cacheris (1984) Fitting curves to data, Byte Magazine, May, 340-360. Carydis, P.G., Drakopoulos, J. and Taflambas, J. (1984). Evaluation of the Corinth strong motion records of February 24 and 25, 1981. Proc. of EAEE, Athens.

Carydis, P.G., Drakopoulos, J., Kalogeras, J., Mouzakis, H., Taflambas, J. and Vougiouka, N. (1989). Analysis of the Kalamata, Greece, strong motion records and correlation with the observed damages. Proc. of XXI General Assembly of E.S.C., 23-27 Aug. 1988, Sofia, Bulgaria, 344-355.

Edaphomihaniki E.P.E., 1998. Geotechnical study of the Thiva area. Ministry of Development, General Secretariat of Research and Technology, Auto-Seismo-Geotech, Vol B, Report 4.1.

EERI. The Athens, Greece Earthquake of September 7, 1999. Special earthquake report Learning from Earthquakes. November 1999. http://www.eeri.org/earthquakes/Reconn/Greece1099/Greece1099.html.

Frankel, A. and L. Wennerberg (1989) Microearthquake spectra from the Anza, California, seismic network: site response and source scaling. Bull. Seis. Soc. Am. 79, 581-609.

Hanks, T.C. (1982) fmax. Bul. Seis. Soc. Am. 72, 1867-1879.

Hanks, T.C. and H. Kanamori (1979) A moment magnitude scale. J. Geophys. Res. 84, 2348-2350.

Hashida, T. Stavrakakis, G. and Shimazaki, K. (1988). Three-dimensional seismic attenuation structure beneath the Aegean region and its tectonic implication. Tectonophysics, $145,43-54$.

Hatzidimitriou, P., Papazachos, C., Kiratzi, A. and Theodoulidis, N.(1993). Estimation of attenuation structure and local earthquake magnitude based on acceleration records in Greece. Tectonophysics, 217, 243-254.

Heaton, T.H. (1982) The 1971 San Fernando earthquake: a double event? Bul. Seis. Soc. Am. 72, 2037-2062.

Hough, S.E., J.G. Anderson, J. Brune, F. Vernon III, J. Berger, J. Fletcher, L. Harr, T. Hanks, and L Barker. Attenuation near Anza, California, Bull. Seis. Soc. Am. 78, 672-691. 
Hudson, D.E. (1979). Reading and interpreting strong motion accelerograms. EERI, Pasadena, California, 1-112.

Hudson, D.E. and Brady, A.G. (1971). Strong motion earthquake accelerograms - Digitized \& plotted data. Vol. IIA. EERL, 71-50, California Institute of Technology, Pasadena, California.

Hutchings, L. and F. Wu (1990). Empirical Green's functions from small earthquakes-A waveform study of locally recorded aftershocks of the San Fernando earthquake, J. Geophys. Res. 95, 1187-1214.

Ioannidou, Eleni, Ioannis Kalogeras, Nicholas Voulgaris, Lawrence Hutchings, and George Stavrakakis(2002). Analysis of Site Response in the Athens Area from the 7 September 1999, Mw=5.9 Athens Earthquake and Aftershock Recordings, and Intensity Observations. submitted to Special Issue on Site Response, Bollettino di Geofisica, Trieste, Italy.

Jarpe, S.P., L.J. Hutchings, T.F. Hauk, and A.F. Shakel (1989) Selected Strong- and WeakMotion Data from the Loma Prieta Earthquake Sequence. Seis Res Letters, 60, 167-176. Joyner, W. B. and D. M. Boore (1982) Measurement characterization and prediction of strong ground motion, in Proc. Earth. Engin. Soil Dyn. II: Recent Advances in Ground Motion Evaluation, ASCE, park City, Utah, 43-102.

Kalogeras, I.S. and Stavrakakis, G.N. (1999). Processing of the strong motion data from the September 7th, 1999 Athens earthquake. National Observatory of Athens, Geodynamic Institute, Publ. No 10 (CD-ROM).

Katsikatsos, G., G. Migiros, M. Triandaphyllis and A. Mettos (1986) Geological Structure of Internal Hellenides. Geological and Geophysical Research Special Issue IGME, pp. 191-212, Athens.

Kouskouna,V., Makropoulos, K., Raftopoulos, D., Malakatas, N., Albini, P., Stucchi, M. and Rubbia, G. (2000) The September 7, 1999, Parnitha earthquake: Macroseismic observations. Abstact in EGU, Sept. 2000, Lisbon, Portugal.

Lachet, C. and P.-Y. Bard (1994) Numerical and Theoretical Investigations on the possibilities of Nakamura's Technique. Journal of Physics of the Earth, 42, 377-397.

Lama, R.D. and V.S. Vutukuri (1978) Handbook on Mechanical Properties of Rocks, V II, R.D. Trans Tech Publications, p. 245, pp. 481.

Lekidis, V., K. Pitilakis, V. Margaris, N. Theodoulidis and A. Moutsakis(1991). The Edessa earthquake of Dec. 21, 1991. Report 91-01, Institute of Engineering Seismology and Earthquake Engineering (ITSAK), 1-68.

Lekkas, E. (2001) The Athens earthquake (7 Sept. 1999): intensity distribution and controlling factors, Engineering Geology 59 (2001) 297-311.

Lindley, Grant T. and Ralph J. Archuleta (1992) Earthquake Parameters and the Frequency Dependence of Attenuation at Colinga, Mammoth Lakes, and the Santa Cruz Mountains, California. J. Geophys. Res. 97, No. B10, 14137- 14154.

Makropoulos, K., Drakopoulos, J. and Kouskoun, V. (1989). The earthquake sequence in 
Volos, Central Greece, April 30, 1985. Analysis of strong motion. IASPEI, (Abstracts), Istanbul, 1989.

Margaris, V.N. (1986). Digitizing errors and filters. Report 86-03, Institute of Engineering Seismology and Earthquake Engineering (ITSAK), 1-43.

Mariolakos, I. and I. Foundoulis (2000) The Athens Earthquake Sept. 7, 1999, the Neotectonic Regime of the Affected Area, Ann. Geol. des Pay Helleniques, Tom. XXXVIII, Fasc. B.

Nelder, J. A. amd R. Mead (1965) A simplex method for function minimization, Computer J., 7, 308 .

Press, William H., Brian P. Flannery, Saul A Teukalsky, and William T. Vetterling (1998) Numerical Recipes (1998), Cambridge University Press.

Papadimitriou, P., G. Kassaras, N. Voulgaris, I. Kassaras, N. Delibasis, and K. Makropoulos (2000) The September 7, 1999 Athens Earthquake Sequence Recorded by the Cornet Network: Preliminary Results of Source Parameters Determination of the Mainshock. Department of Geophysics, University of Athens, 15784 Athens, Greece.

Papadopoulos, G.A., G. Drakatos, D. Papanastassiou, I. Kalogeras, G. Stavrakakis (2000) Preliminary Results about the Catastrophic Earthquake of 7 September 1999 in Athens, Greece. Seis. Res. Let. 71, No. 3, pp.318-329.

Papazachos C. (1992). Anisotropic radiation modeling of macroseismic intensities for estimation of the attenuation structure of the upper crust in Greece. Pageoph, 138, 445-469.

Protonotarios I. (1999) Preliminary conclusions from the Sept. 9, 1999 Earthquake. Workshop on The Sept. 9, 1999 Athens Earthquake, November 2, 1999 Athens, Greece

Rollins, K.M., M.D. Mchood, R.D. Hryciw, and M. Homolka (1994) Ground Response on Treasure Island. Strong Ground Motion. pp. A109-A121.

Stavrakakis, G.N., Kalogeras, I.S. and Drakopoulos, J.C. (1993). Preliminary analysis of Greek accelerograms recorded at stations of NOA's network: Time period 1973 - 1990. Proc. 2nd Congress Hellenic Geophys. Union, Florina, Greece, 5-7 May, 175-191.

Trifunac, M.D. and Lee, V.W. (1973). Routine computer processing of strong-motion accelerograms. EERL, 73-03.

Trifunac, M.D. and Lee, V.W. (1979). Automatic digitalization and processing of strongmotion accelerograms. Part I. Univ. Southern California, Tech. rep. CE, 79-151.

Trifunac, M.D., Udwadia, F.E. and Brady, A.G. (1973). Analysis of errors in digitized strong-motion accelerograms. Bull. Seism. Soc. Am., 63,

Tsamis, 1999. Study for the development and extension of the building of the Nuclear Technology and Radiation Protection Institute.Nuclear Center for Scientific Research "Demokritos".

Tselentis, G-Akis and Jiri Zahradnik (1999) Aftershock Monitoring of the Athens Earthquake of 7 September 1999. Seis. Res. Let., 71, No. 3, pp 330-337. 
Tumarkin, A.G. and R.J. Archuleta (1997) Recent Advances in Prediction and Processing of Strong Motions, Natural Hazards, 15, 199-215.

Voulgaris, N., I. Kassaras, P. Papadimïtriou, and N. Delibasis (2000) Preliminary Results of the Athens September 7, 1999 Aftershock Sequence.

Wennerberg, (1983) " ... " BSSA Notes, Santa Barbara

Wu, F. T. and Ari Ben-Menahem (1965) Surface wave radiation pattern and source mechanism of the September 1, 1962, Iran earthquake. Journal of Geophysical Research, vol.70, no.16, pp.3943-3949, 1965.

\section{Acknowledgments}

This project was partially supported by the Lawrence Livermore National Laboratory, Campus/Laboratory Collaboration Project, and under the auspices of the U.S. Department of energy by the University of California, under contract No. W-7405-Eng-48. It was partially funded by Caltrans under contract \#59A0238 for site response analysis. 
Table 1: Stations (from Ioannidou et al., 2002)

\begin{tabular}{|c|c|c|c|c|c|c|c|}
\hline Station & Latitude & $\begin{array}{c}\text { Longi- } \\
\text { tude }\end{array}$ & Location & $\begin{array}{r}\text { Orient. } 1, \\
. t+90.0 \\
\end{array}$ & \begin{tabular}{|c|} 
No. \\
events
\end{tabular} & $\begin{array}{l}\text { Geol } \\
\text { categ }\end{array}$ & \begin{tabular}{|c|} 
site specific \\
$t_{g}^{*}$ \\
\end{tabular} \\
\hline ATHA $^{+}$ & $38.00^{\circ} \mathrm{N}$ & $23.77^{\circ} \mathrm{E}$ & $\begin{array}{l}\text { Neo Psihiko;3-s reinforced } \\
\text { concrete (RC); }-13 \mathrm{~m}\end{array}$ & $\mathrm{~N} 180^{\circ} \mathrm{E}$ & 16 & $\mathrm{c}$ & $.0031 \pm .0002$ \\
\hline $\mathrm{ATHB}^{++}$ & $37.93^{\circ}$ & $23.70^{\circ}$ & NeoFaliro; Planetarium,3-s RC & $120^{\circ}$ & 4 & $\mathrm{c}$ & $.0025 \pm .0012$ \\
\hline $\operatorname{COUR}^{* *}$ & $38.10^{\circ}$ & $23.65^{\circ}$ & Fili, Soccer Stadium & $0^{\circ}$ & 5 & $\mathrm{a}$ & $.0027 \pm .0008$ \\
\hline$\overline{\mathrm{DEKL}^{++}}$ & $38.10^{\circ}$ & $23.78^{\circ}$ & Dekelia, Air Base, 1-story & $175^{0 *+}$ & 4 & $\mathrm{c}$ & $.0271 \pm .0097$ \\
\hline $\mathrm{DFNA}^{+}$ & $37.95^{\circ}$ & $23.74^{\circ}$ & Dafni; Metro station, $-14 \mathrm{~m}$ & $155^{0 *+}$ & 1 & $\mathrm{c}$ & $.0086 \pm$ \\
\hline $\mathrm{DMKA}^{+}$ & $37.99^{\circ}$ & $23.82^{\circ}$ & $\begin{array}{l}\text { Ag.Paraskevi; Research center, } \\
\text { 1-story RC }\end{array}$ & $135^{\circ}$ & 4 & $\mathrm{~b}$ & $.0024 \pm---$ \\
\hline FIXA $^{+}$ & $37.96^{\circ}$ & $23.73^{\circ}$ & $\begin{array}{l}\text { Sygrou-Fix; Metro station, } \\
-15 \mathrm{~m}\end{array}$ & $140^{\circ}$ & 4 & $\mathrm{c}$ & $.0046 \pm$ \\
\hline PEFK $^{* *}$ & $38.08^{\circ}$ & $23.62^{\circ}$ & $\begin{array}{l}\text { Thriassion plain, Ware House } \\
\text { 1-story }\end{array}$ & $0^{\circ}$ & 6 & $\bar{c}$ & $.0037 \pm .0014$ \\
\hline $\mathrm{PNTA}^{+}$ & $38.00^{\circ}$ & $23.79^{\circ}$ & Papagos; Metro station, $-15 \mathrm{~m}$ & $135^{\circ}$ & 1 & $\bar{c}$ & $.0067 \pm--$ \\
\hline $\mathrm{RFNA}^{+}$ & $38.02^{\circ}$ & $23.99^{\circ}$ & Private building, 1-s wood & $250^{\circ} *^{+}$ & 1 & $\mathrm{~b}$ & $.0048 \pm \cdots$ \\
\hline $\mathrm{RNTA}^{++}$ & $37.96^{\circ}$ & $23.68^{\circ}$ & Rentis; Town Hall, 2-s RC & $210^{\circ}$ & 3 & $\mathrm{c}$ & $.0075 \pm--$ \\
\hline $\mathrm{SGMA}^{+}$ & $37.98^{\circ}$ & $23.74^{\circ}$ & Syntagma; Metro station, $-7 \mathrm{~m}$ & $010^{\circ}$ & 7 & $\mathrm{~b}$ & $.0051 \pm .0014$ \\
\hline $\mathrm{SGMB}^{+}$ & $37.98^{\circ}$ & $23.74^{\circ}$ & $\begin{array}{l}\text { Syntagma; Metro station, } \\
-26 \mathrm{~m}\end{array}$ & $135^{\circ}$ & 3 & $\mathrm{~b}$ & $.0076 \pm \cdots$ \\
\hline SPLA $^{+}$ & $38.00^{\circ}$ & $23.71^{\circ}$ & Sepolia; Metro station, $-13 \mathrm{~m}$ & $320^{\circ}$ & 18 & $\mathrm{c}$ & $.0053 \pm .0017$ \\
\hline SPLB $^{+}$ & $38.00^{\circ}$ & $23.71^{\circ}$ & Sepolia; Metro station, 3-s steel & $320^{\circ}$ & 19 & $\bar{c}$ & $.0046 \pm .0021$ \\
\hline FILI** & $38.12^{\circ}$ & $23.68^{\circ}$ & Fili Monastery, free field & $0^{\circ} !$ & 6 & $\mathrm{~b}$ & $.0034 \pm .0015$ \\
\hline THVC $^{+}$ & $38.32^{\circ}$ & $23.32^{\circ}$ & Thiva; Town Hall, 3-s RC & $180^{\circ}$ & 5 & $\mathrm{~b}$ & $.0027 \pm .0016$ \\
\hline PSAR** & $38.09^{\circ}$ & $23.56^{\circ}$ & Goritsa, house, ground fl, RC & $0^{\circ}$ & 6 & $\mathrm{c}$ & $.0166 \pm .0010$ \\
\hline$\overline{\mathrm{MAGO} * *}$ & $38.08^{\circ}$ & $23.52^{\circ}$ & Magoula, 1-story RC & $0^{\circ} !$ & 6 & $\bar{a}$ & $.0056 \pm .0019$ \\
\hline \begin{tabular}{|l|} 
STEF** \\
NOOE bad \\
\end{tabular} & $38.17^{\circ}$ & $23.55^{\circ}$ & Stefani, Storage, ground fl, $\mathrm{RC}$ & $0^{\circ} !$ & 5 & $\mathrm{~b}$ & $.0111 \pm .0032$ \\
\hline $\mathrm{ZOFR}^{* *}$ & $38.07^{\circ}$ & $23.69^{\circ}$ & Zofria; free field & $0^{\circ}$ & 6 & $\bar{a}$ & $.0026 \pm .0011$ \\
\hline $\mathrm{NEOK}^{* *}$ & $38.05^{\circ}$ & $23.63^{\circ}$ & Neokista ground $\mathrm{fl}, \mathrm{RC}$ & $0^{\circ} !$ & 6 & $\mathrm{a}$ & $.0024 \pm .0007$ \\
\hline
\end{tabular}

+ NOAIG station

++ NOAIG, did not record main event

** Univ. of Athens data, did not record main event

*+ $t$ component -90.0 from .1 component

! polarity may be reversed 
Table 2: Geology of recording rites (from Ioannidou et al., 2002)

\begin{tabular}{|c|c|c|c|c|}
\hline Site & Categ & Geology & Dist & Intensity* \\
\hline ATHA & (c) & $\begin{array}{l}\text { Tertiary deposits. } 0-2 \mathrm{~m} \text { fill material, } 2-6 \mathrm{~m} \text { poorly } \\
\text { cemented conglomerate, } 6-20 \mathrm{~m} \text { very weathered } \\
\text { sandstone, } 20-30 \mathrm{~m} \text { sandstone. (Attiko Metro, 1999) }\end{array}$ & 25 & V+, Filothei \\
\hline ATHB & (c) & $\begin{array}{l}\text { Holocene deposits. } 0-1 \mathrm{~m} \text { soil, } 1-8 \mathrm{~m} \text { brown sandy } \\
\text { clay with pebbles, } 8-12 \mathrm{~m} \text { brown stiff sandy clay, } \\
12-20 \mathrm{~m} \text { brown stiff clay. (Geomihaniki E.P.E., } \\
1999 \text { ). }\end{array}$ & 25 & $\begin{array}{l}\text { V+, Alimos; } \\
\text { VI, Ag. Dimi- } \\
\text { trios }\end{array}$ \\
\hline COUR & (a) & $\begin{array}{l}\text { Middle Triassic - Lower Jurassic (Mesozoic). Dolo- } \\
\text { mite-limestone formation, considerably fractured } \\
\text { and folded. In the station area this formation over- } \\
\text { lies the Permian formation with a maximum thick- } \\
\text { ness of } 50 \mathrm{~m} \text {. }\end{array}$ & 18 & VIII** \\
\hline $\mathrm{DEKL}$ & (c) & Recent Deposits & 24 & VIII $^{* *}$ \\
\hline DFNA & (c) & $\begin{array}{l}\text { Alluvium schist; 0-3.5m alluvial deposits, } 3.5-9 \mathrm{~m} \\
\text { Athenian schist - sandstone medium weathered, 9- } \\
30 \mathrm{~m} \text { Athenian schist - sandstone slightly weathered. } \\
\text { (Attiko Metro, 1999) }\end{array}$ & 26 & $\begin{array}{l}\mathrm{V}+\text {, Agios } \\
\text { and Dimitrios }\end{array}$ \\
\hline$\overline{D M K A}$ & (b) & $\begin{array}{l}\text { 0-1m fill materials, } 1-3 \mathrm{~m} \text { conglomerate altered to } \\
\text { clayey sand gravel, } 3-4 \mathrm{~m} \text { brown schist with many } \\
\text { cracks and calcareous veins, } 4-12 \mathrm{~m} \text { very humified } \\
\text { peridoite, altered locally to clayey - loose or synectic } \\
\text { - sand gravels. The site according to the New Seismic } \\
\text { Resistant Code could be characterized as very altered } \\
\text { rock sites, which are classified as granular soils from } \\
\text { the engineering point of view (Tsamis, 1999). }\end{array}$ & 29 & V+, Vyronas \\
\hline$\overline{\text { FIXA }}$ & (c) & $\begin{array}{l}\text { Alluvium schist; } 0-2 \mathrm{~m} \text { fill materials, } 2-6.5 \mathrm{~m} \text { Athe- } \\
\text { nian schist - calcareous siltstone, } 6.511 \mathrm{~m} \text { Athenian } \\
\text { schist - quartzy siltstone, } 11-14.5 \mathrm{~m} \text { siltstone and } \\
\text { lime stone, } 14.5-30 \mathrm{~m} \text { siltstone, calcareous siltstone } \\
\text { and quartzy siltstone. (Attiko Metro, 1999) }\end{array}$ & 25 & $\mathrm{VII} * *$ \\
\hline PEFK & (c) & Quaternary deposits & 17 & $\mathrm{VII}{ }^{* *}$ \\
\hline PNTA & (c) & $\begin{array}{l}\text { Tertiary deposits; 0-3m fill material, 3-20m slightly } \\
\text { cemented silty clay, 20-29m shales. (Attiko Metro, } \\
1999 \text { ) }\end{array}$ & 26 & V+, Filothei \\
\hline$\overline{\text { RFNA }}$ & (b) & Tertiary deposits limestone & 40 & $\begin{array}{l}\text { V, Lavrio; } \\
\text { Keratea V+ }\end{array}$ \\
\hline
\end{tabular}


Table 2: Geology of recording rites (from Ioannidou et al., 2002)

\begin{tabular}{|c|c|c|c|c|}
\hline RNTA & (c) & $\begin{array}{l}\text { Alluvium schist; } 0-1.5 \mathrm{~m} \text { soil, } 1.5-4 \mathrm{~m} \text { sandy silt- } \\
\text { stone, } 4-7.5 \text { brown clay, } 7.5-13 \mathrm{~m} \text { mixture of sand, } \\
\text { clay and silt, } 13-15.5 \mathrm{~m} \text { sand, } 15.5-20 \mathrm{~m} \text { sand and } \\
\text { gravels, } 20-23.5 \mathrm{~m} \text { stiff marl. (IoKede, } 1981 \text { ) }\end{array}$ & 23 & VI \\
\hline SGMA & (b) & $\begin{array}{l}\text { Schist; } 0-12 \mathrm{~m} \text { Athenian schist - sandstone slightly } \\
\text { weathered, } 12-28 \mathrm{~m} \text { Athenian schist - sandstone } \\
\text { slightly weathered and fractured. (Attiko Metro, } \\
\text { 1999) }\end{array}$ & 25 . & $\mathrm{V}+$ \\
\hline SGMB & (b) & $\begin{array}{l}\text { Schist; 0-12m Athenian schist - sandstone slightly } \\
\text { weathered, } 12-28 \mathrm{~m} \text { Athenian schist - sandstone } \\
\text { slightly weathered and fractured. (Attiko Metro, } \\
\text { 1999) }\end{array}$ & 25 & $\mathrm{~V}+$ \\
\hline SPLA & (c) & $\begin{array}{l}\text { Alluvium schist; } 0-6.5 \mathrm{~m} \text { fill material, } 6.5-13.5 \mathrm{~m} \\
\text { slightly cemented silty clay, } 13.5-17 \mathrm{~m} \text { strongly } \\
\text { cemented conglomerate, } 17-22.5 \mathrm{~m} \text { sandy siltstone, } \\
22.5-24 \mathrm{~m} \text { calcareous siltstone. (Attiko Metro, } 1999 \\
\end{array}$ & 22 & VII \\
\hline SPLB & (c) & $\begin{array}{l}\text { Manmade deposits; } 0-6.5 \mathrm{~m} \text { fill material, } 6.5-13.5 \mathrm{~m} \\
\text { slightly cemented silty clay, } 13.5-17 \mathrm{~m} \text { strongly } \\
\text { cemented conglomerate, } 17-22.5 \mathrm{~m} \text { sandy siltstone, } \\
22.5-24 \mathrm{~m} \text { calcareous siltstone. (Attiko Metro, } \\
1999 \text { ) }\end{array}$ & 22 & VII \\
\hline$\overline{\text { FILI }}$ & (b) & $\begin{array}{l}\text { Schist; Upper Palaeozoic (Permian). TRhis forma- } \\
\text { tion consists of alterations of phyllites, sandstones, } \\
\text { shales and graywackes, which appear significantly } \\
\text { fractured folded and weathered, resulting to the } \\
\text { existence of soil cover of important thickness. Due } \\
\text { to the long history of tectonic deformation in the } \\
\text { area, this formation is overthrusted on the Triassic- } \\
\text { Jurassic limestone formation. }\end{array}$ & 19 & VIII, Fili \\
\hline THVC & (b) & $\begin{array}{l}\text { Pleistocene deposits; } 0-2 \mathrm{~m} \text { slightly cemented silty } \\
\text { clay, } 2-4 \mathrm{~m} \text { poorly cemented conglomerate, } 4-6 \mathrm{~m} \\
\text { strongly cemented conglomerate, } 6-24 \mathrm{~m} \text { conglom- } \\
\text { erate (limestone pebbles in a reddish silty clay). } \\
\text { (Edaphomihaniki E.P.E., 1998) }\end{array}$ & 39 & $\begin{array}{l}\text { V, Thespies; } \\
\text { V, Akrefinio; } \\
\text { IV, Istiaia }\end{array}$ \\
\hline PSAR & (c) & $\begin{array}{l}\text { Neogene-Quaternary; Pioquaternary deposits of } \\
\text { considerable depth, which mainly represents the } \\
\text { product of erosion from the surrounding geological } \\
\text { formations. Due to the unconsolidated nature and } \\
\text { the sandy and silty character of these deposits this } \\
\text { area can be characterized as a "soft" site" }\end{array}$ & 17 & VII** \\
\hline
\end{tabular}


Table 2: Geology of recording rites (from Ioannidou et al., 2002)

\begin{tabular}{|c|c|l|l|l|}
\hline MAGO & (a) & $\begin{array}{l}\text { Limestone, Upper Cretaceous Limestone, uncom- } \\
\text { fortably overlies the dolomites and limestones of } \\
\text { Mi-Triassic - Lower Jurassic. }\end{array}$ & 18 & VII** \\
\hline STEF & (b) & $\begin{array}{l}\text { Schist; Upper Palaeozoic (Permian). This formation } \\
\text { consists of alterations of phyllites, sandstones, } \\
\text { shales and graywackes, which appear significantly } \\
\text { fractured folded and weathered, resulting to the } \\
\text { existence of soil cover of important thickness. Due } \\
\text { to the long history of tectonic deformation in the } \\
\text { area, this formation is overthrusted on the Triassic- } \\
\text { Jurassic limestone formation. }\end{array}$ & VII** \\
\hline ZOFR & (a) & $\begin{array}{l}\text { Limestone, Middle Triassic - Lower Jurassic } \\
\text { (Mesozoic). Dolomite-limestone formation, consid- } \\
\text { erably fractured and folded. In the station area this } \\
\text { formation overlies the Permian formation with a } \\
\text { maximum thickness of 50 m. }\end{array}$ & 19 & VIII** \\
\hline NEOK & (a) & $\begin{array}{l}\text { Limestone; Lower Jurassic (Mesozoic). Dolomite- } \\
\text { limestone formation, considerably fractured and } \\
\text { folded. }\end{array}$ & 18 & VII** \\
\hline
\end{tabular}

*Intensities on the Modified Mercalli Scale calculated by the NOGIA for the main event (Kalogeras and Stavrakakis 1999), and names of districts nrear the station where the intensity was evaluated

**Intensity values interpreted from isoseismals in Figure 3. 
Table 3: Events used in the study (from Ioannidou et al., 2002)

\begin{tabular}{|c|c|c|c|c|c|c|c|c|}
\hline Earthquake & Latitude & Longitude & $\begin{array}{c}\text { Depth } \\
\mathrm{km}\end{array}$ & Ml & $\begin{array}{c}\text { Mox } 10^{21} \\
\text { dyne-cm }\end{array}$ & $\begin{array}{c}\mathrm{fc} \\
\mathrm{Hz}\end{array}$ & \begin{tabular}{l}
\multicolumn{3}{c}{ mechanism } \\
STK DP SV
\end{tabular} & $\begin{array}{l}\text { no. } \\
\text { stat }\end{array}$ \\
\hline 1999/09/07 11:56:51* & 38.08 & 23.58 & 16.8 & 5.4 & 94900 & 0.45 & $113^{\circ} 39^{\circ}-90^{0^{*}}$ & 10 \\
\hline 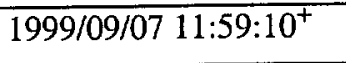 & 38.15 & 23.59 & $5.0^{* *}$ & $* * *$ & 228 & 3 & & 6 \\
\hline 1999/09/07 12:00:29+ & 37.92 & 23.78 & 17.8 & $* * *$ & 176 & 2 & & 6 \\
\hline $1999 / 09 / 0712: 01: 57^{+}$ & 38.07 & 23.75 & $5.0^{* *}$ & $* * *$ & 28.5 & 3 & & 2 \\
\hline 1999/09/07 12:03:54t & 38.01 & 23.47 & 5.2 & $3.5^{!}$ & $73 !$ & 6 & & 1 \\
\hline $1999 / 09 / 07 \quad 12: 05: 12^{+}$ & 38.11 & 23.69 & $5.0^{* *}$ & $* * *$ & 228 & 2 & & 4 \\
\hline $1999 / 09 / 0712: 08: 11^{+}$ & 37.82 & 23.71 & $5.0^{* *}$ & $* * *$ & 269 & 4 & & 4 \\
\hline $1999 / 09 / 0712: 16: 10^{+}$ & 37.96 & 23.76 & 17.0 & $* * *$ & 328 & 4 & & 4 \\
\hline $1999 / 09 / 07 \quad 12: 20: 25^{+}$ & 38.09 & 23.65 & $5.0^{* *}$ & $* * *$ & 344 & 5 & & 1 \\
\hline $1999 / 09 / 0713: 02: 02^{+}$ & 38.07 & 23.62 & 5.0 & $* * *$ & 26.3 & 4 & & 2 \\
\hline $1999 / 09 / 0713: 05: 48^{+}$ & 38.13 & 23.51 & 18.2 & $* * *$ & 322 & 3 & & 1 \\
\hline $1999 / 09 / 0715: 35: 33^{*^{+}}$ & 38.01 & 23.48 & 10.0 & 3.9 & 150 & 3 & & 6 \\
\hline $1999 / 09 / 0715: 42: 52^{*^{+}}$ & 38.07 & 23.45 & 3.0 & 3.5 & 72.8 & 6 & & 1 \\
\hline $1999 / 09 / 0717: 19: 21^{*}$ & 38.11 & 23.72 & 16.2 & 3.8 & 260 & 3 & $114^{\circ} 30^{\circ}-87^{\circ}$ & 4 \\
\hline 1999/09/07 20:44:55* & 38.19 & 23.72 & 21.0 & 4.4 & 611 & 2 & & 3 \\
\hline 1999/09/08 03:21:32* & 38.09 & 23.83 & 14.1 & 3.7 & 313 & 3 & & 7 \\
\hline 1999/09/08 03:35:20* & 38.12 & 23.89 & 13.0 & 3.7 & 487 & 5 & $106^{\circ} 30^{\circ}-74^{\circ}$ & 3 \\
\hline 1999/09/08 11:14:29* & 37.99 & 23.59 & 7.0 & 3.1 & 46.5 & 3 & & 2 \\
\hline \begin{tabular}{|l|}
$1999 / 09 / 08 ~ 12: 55: 01 *$ \\
\end{tabular} & 38.14 & 23.74 & 19.9 & 4.0 & 965 & 2 & $330^{\circ} 70^{\circ}-30^{\circ}$ & 2 \\
\hline 1999/09/08 13:18:21* & 38.08 & 23.81 & 9.2 & 3.7 & 99.8 & 3 & & $\mid 4$ \\
\hline \begin{tabular}{|l}
$1999 / 09 / 08$ 16:50:37* \\
\end{tabular} & 38.19 & 23.91 & 1.4 & 3.6 & 185 & 4 & $113^{\circ} 28^{\circ}-67^{\circ}$ & 1 \\
\hline \begin{tabular}{|l}
$1999 / 09 / 0816: 54: 08^{*}$ \\
\end{tabular} & 38.14 & 23.79 & 19.4 & 3.5 & 350 & 3 & $310^{\circ} 50^{\circ}-20^{\circ}$ & 1 \\
\hline $1999 / 09 / 1014: 49: 57^{++}$ & 38.08 & 23.67 & 9.1 & 3.7 & 444 & 3 & $319^{\circ} 70^{\circ}-79^{\circ}$ & 10 \\
\hline $1999 / 09 / 1319: 45: 15^{++}$ & 38.06 & 23.65 & 9.1 & 3.1 & 95.1 & 3 & $109^{\circ} 50^{\circ}-74^{\circ}$ & 11 \\
\hline $1999 / 09 / 1608: 12: 10^{++}$ & 38.06 & 23.66 & 7.9 & 3.1 & 93.5 & 3 & $120^{\circ} 54^{\circ}-89^{\circ}$ & 11 \\
\hline $1999 / 09 / 2019: 58: 0{ }^{*+}$ & 37.96 & 23.53 & 7.0 & 2.9 & 22.2 & 3 & & 10 \\
\hline $1999 / 09 / 2020: 17: 25^{++}$ & 37.97 & 23.64 & 8.8 & 2.9 & 2.90 & 7 & $250^{\circ} 65^{\circ}-48^{\circ}$ & 8 \\
\hline 1999/10/03 17:03:34 & 38.09 & 23.75 & 9.0 & 3.5 & 252 & 3 & $159^{\circ} 65^{\circ}-48^{\circ}$ & 10 \\
\hline $2000 / 03 / 2303: 09: 18^{*^{+}}$ & 38.08 & 23.74 & 15.0 & 3.5 & 412 & 3 & $120^{\circ} 54^{\circ}-89^{\circ}$ & 4 \\
\hline
\end{tabular}

"location from Papadopoulos et al. (2000)

+ Location obtained from permanent networks in Greece and s-p arrival time intervals

++ Solution from combined data of Univ. of Athens and National Observatory of Athens

*+ Locations routinely calculated by NOAIG from their permanent Greek network

** Depth fixed

*** Magnitude obtained from moment/magnitude relationship

'Moment and magnitude obtained from spectral overlay with event 1999/09/07 15:42:52 


\section{Figures}

Figure 1. The morphology of the Athens area, the epicenter of the main shock, and locations of stations and events used in this study (from Ioannidou et al., 2002).

Figure 2. Geology of the lower border area of Attica (modified from Katsikatsos et al., 1986), station locations, and epicenter of main event (from Ioannidou et al., 2002).

Figure 3. Isoseismal intensity from the earthquake in Modified Mercalli Scale, and individual intensity values for the same area as specified in Table 2 (from Ioannidou et al., 2002).

Figure 4. Plot of calculated site specific $t^{*}$ values at each station. The circle size corresponds to $t_{g}^{*}$ values (from Ioannidou et al., 2002).

Figure 5. Corrected spectra, as described in text, of all recordings for six events, and the fit of the simultaneous inversion for moment, source corner frequency, and individual station $t^{*}$ (from Ioannidou et al., 2002).

Figure 6. Corrected spectra, as described in text, of all recordings for six events, and the fit of the simultaneous inversion for moment, source corner frequency, and individual station $t^{*}$ (from Ioannidou et al., 2002).

Figure 7. Corner frequency values as a function of moment for the events in this study (triangles). and the corner frequency relationship predicted by a Brune source model with 100 bar stress drop (solid line) (from Ioannidou et al., 2002). 


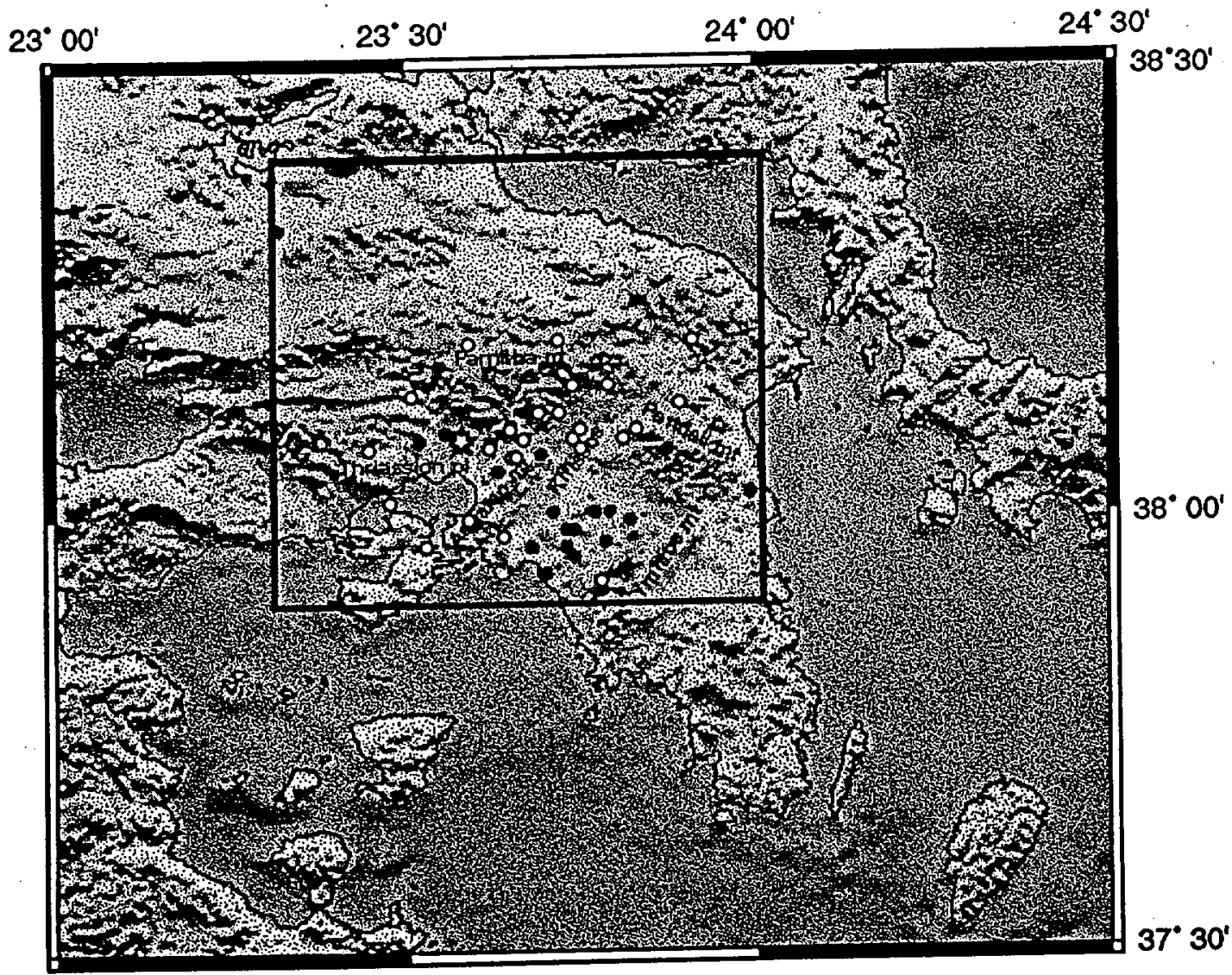

\begin{tabular}{|lllll|}
\hline E Epicenter of Main Event & \multicolumn{3}{c|}{$\mathrm{km}$} \\
\cline { 2 - 5 } - Aftershocks & & & \\
- Stations & 0 & 10 & 20 \\
\hline
\end{tabular}




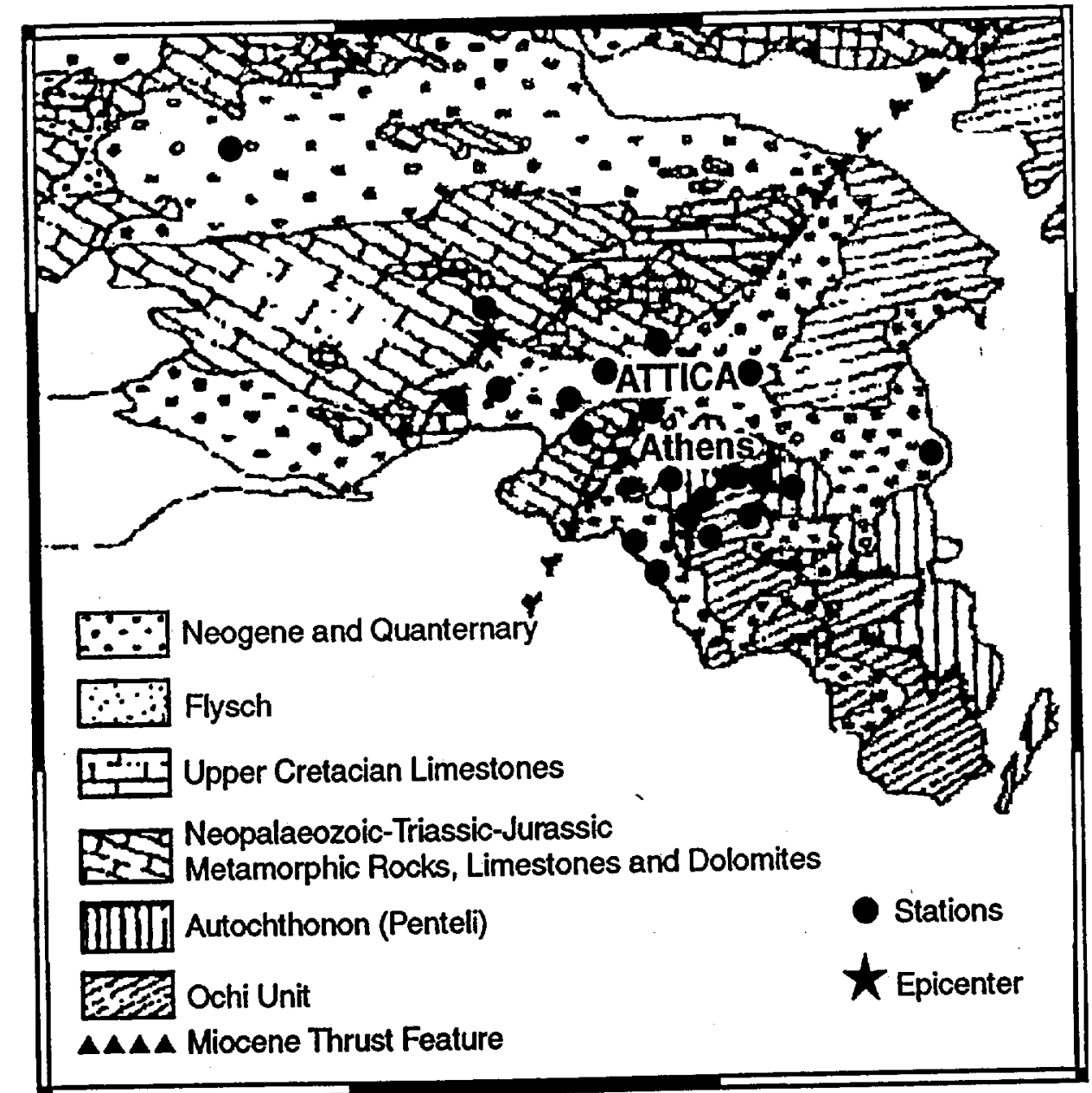

(Modified after Katsikatsos et al., 1986) 


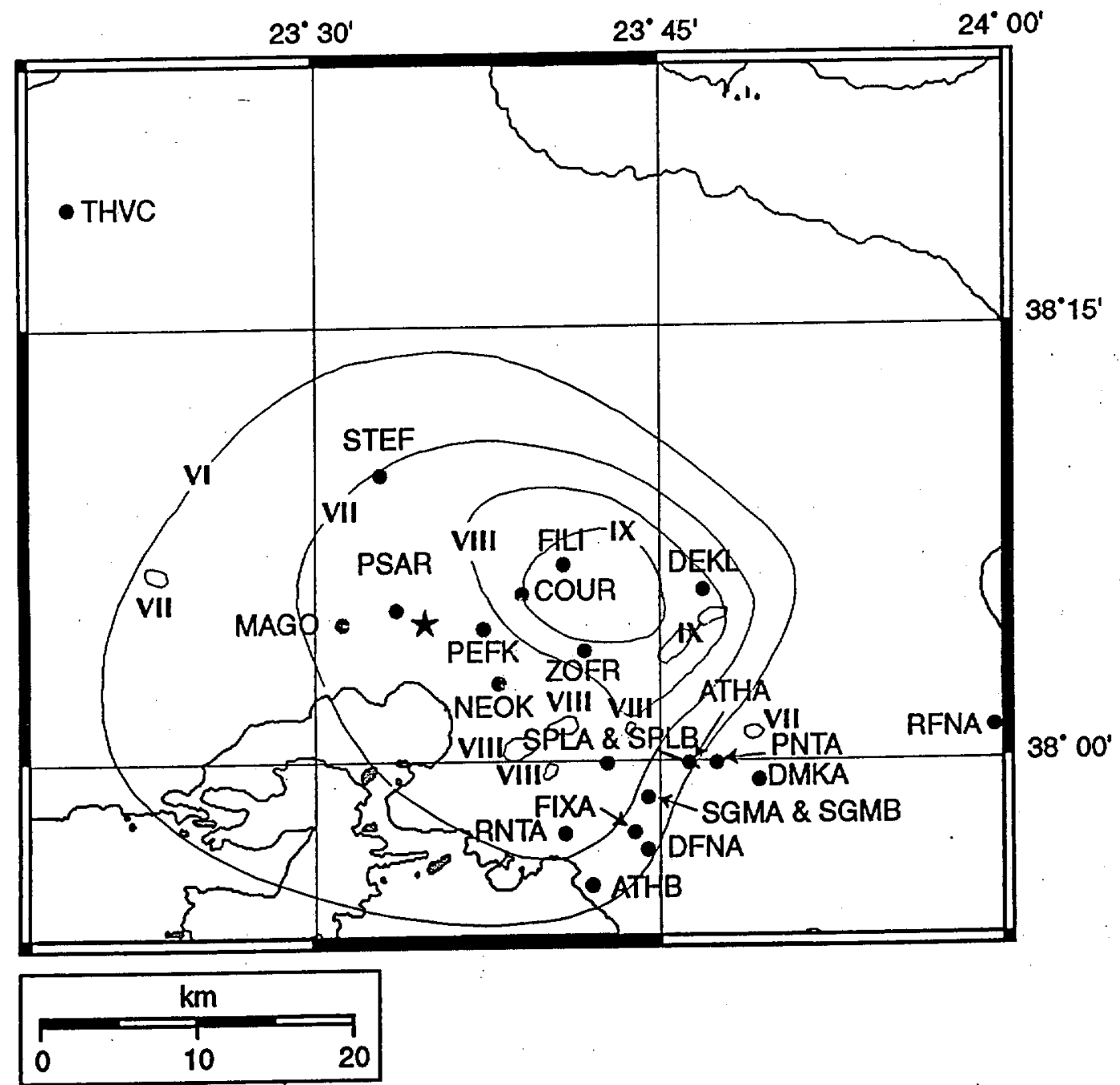

Figure 03

Hutchings 


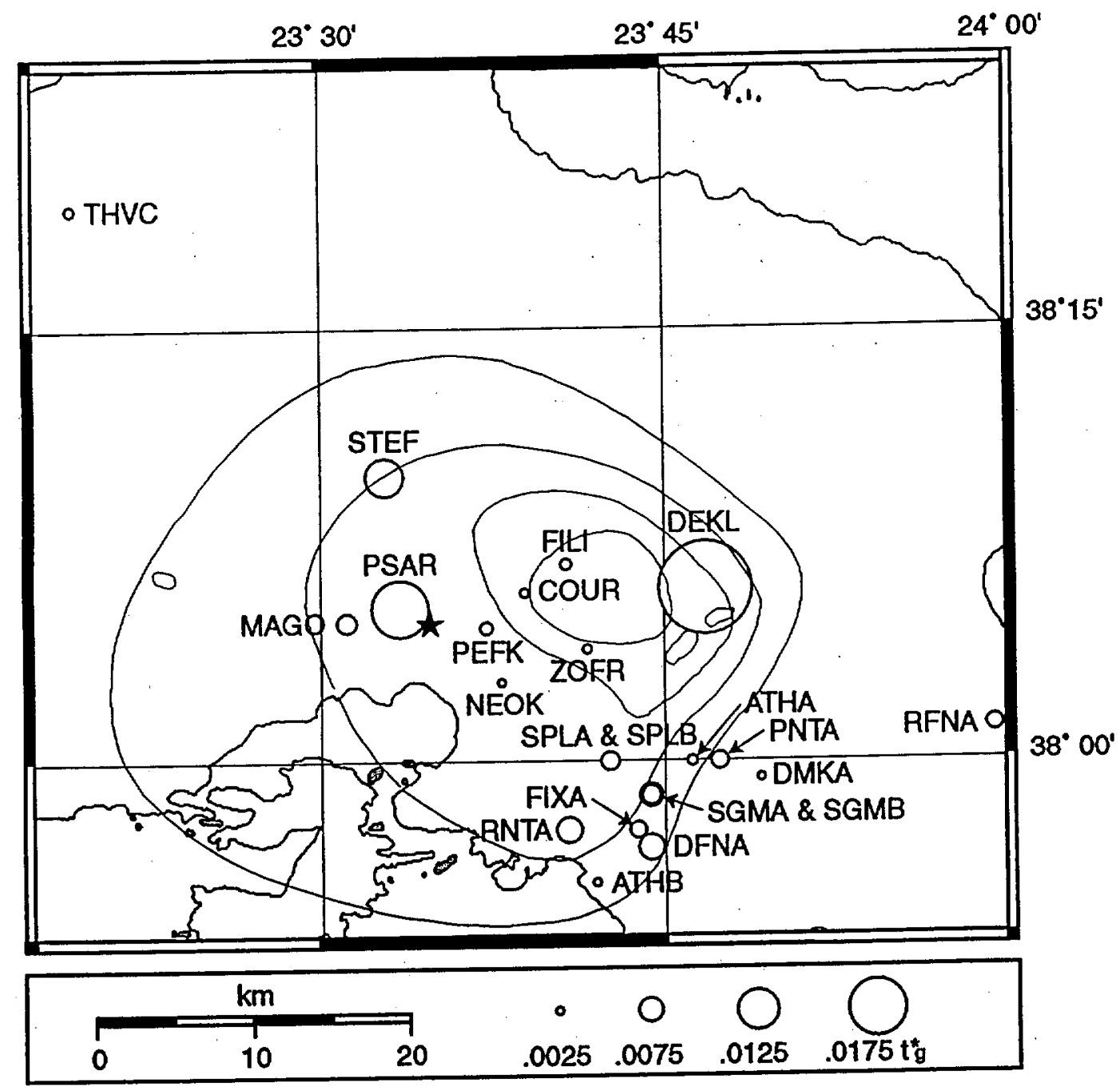



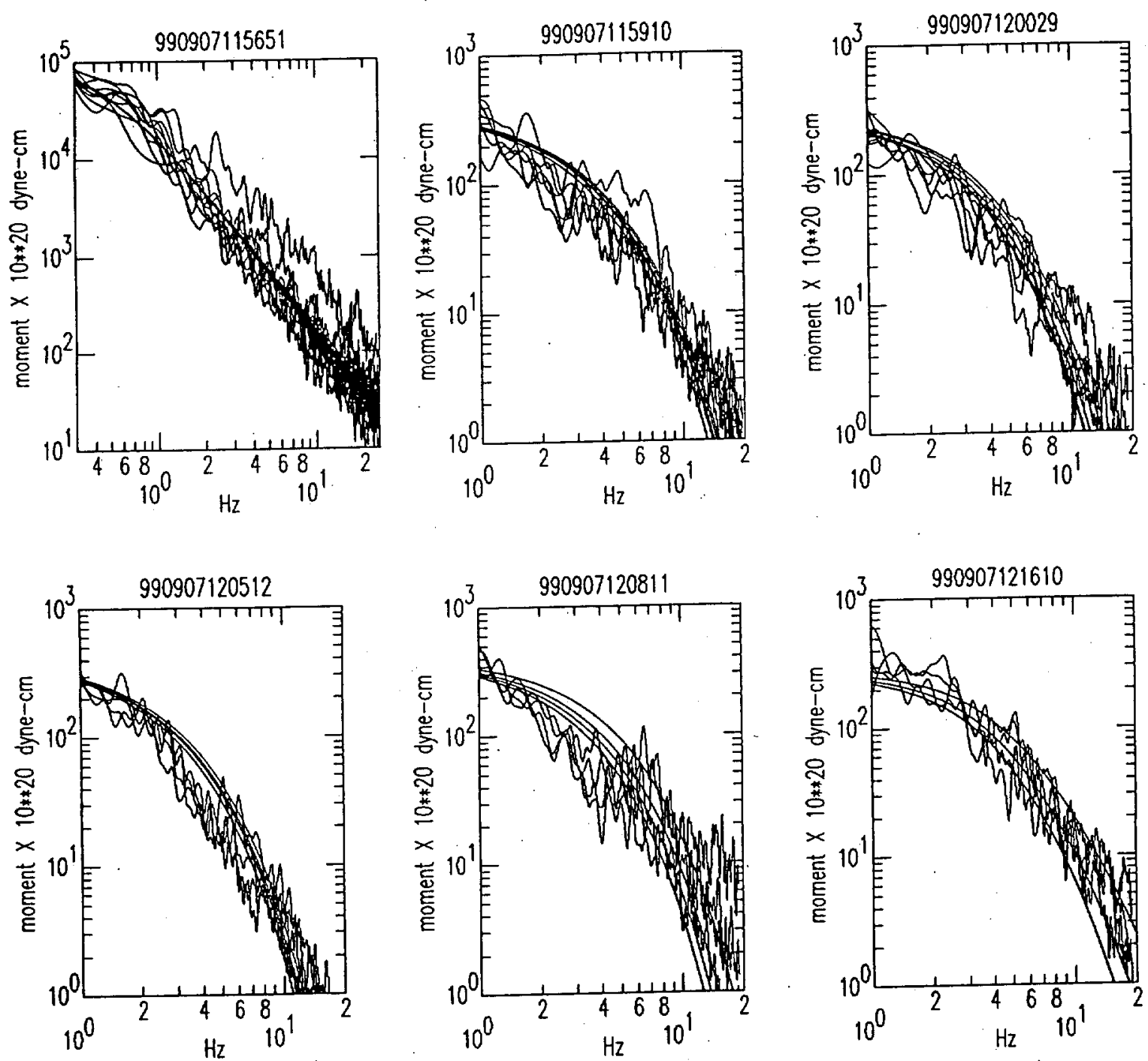

Figure 05

Hutchings 

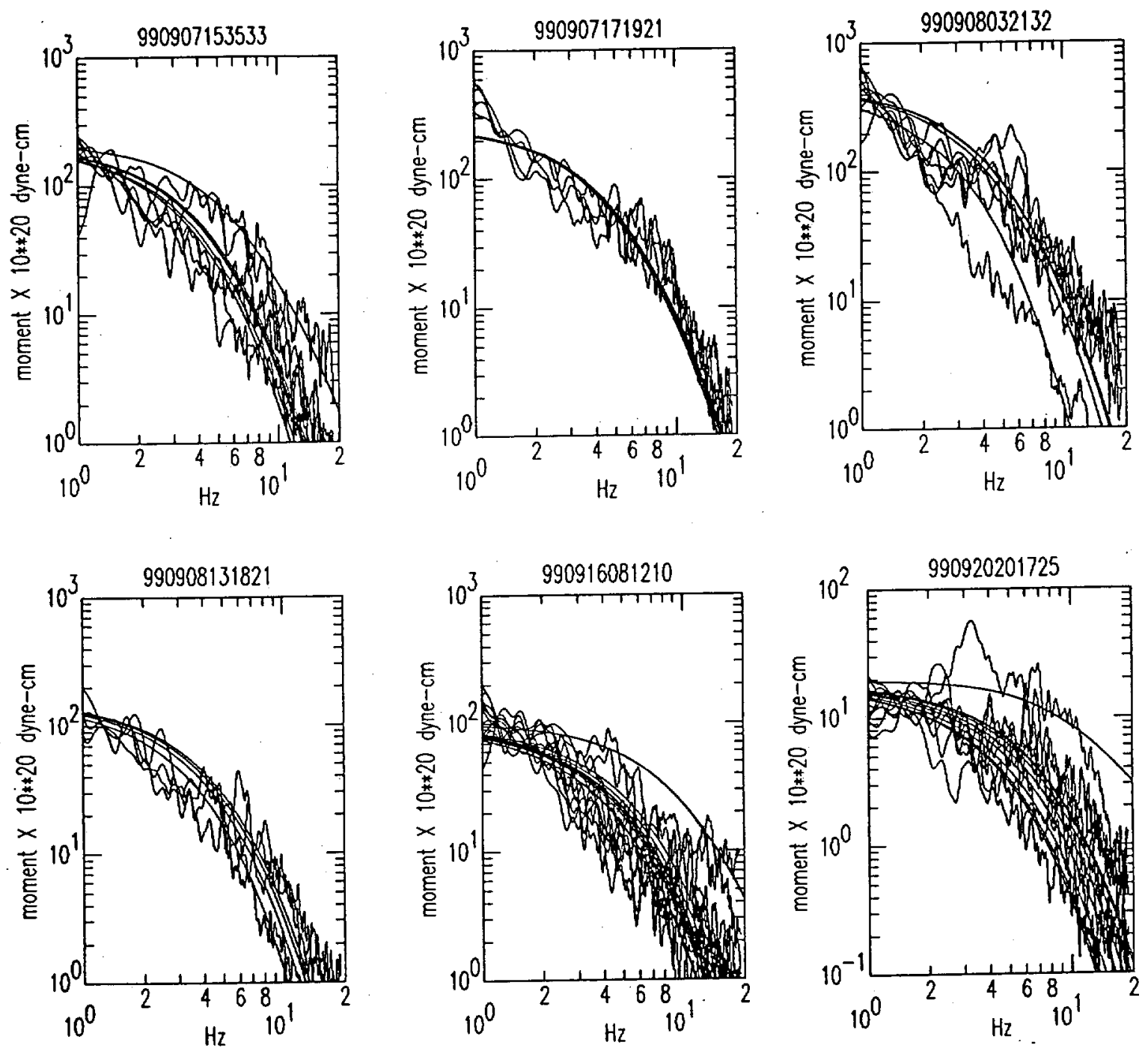


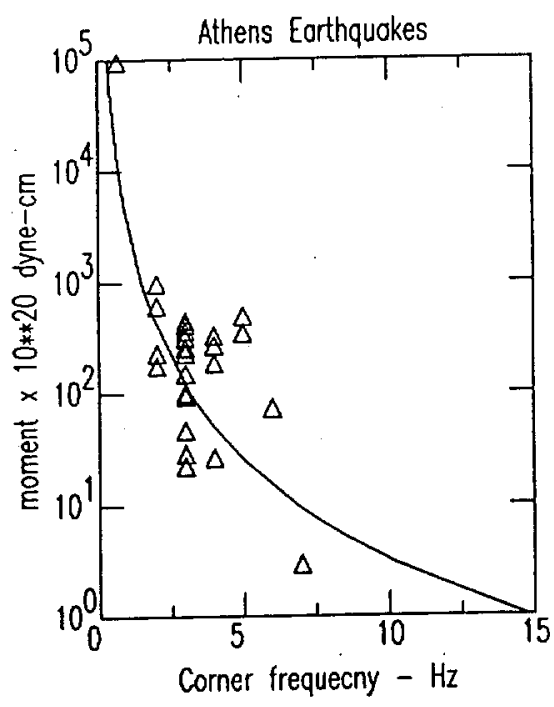

Figure 07

Hutchings 
Appendix I

Program NetMoment 
$\mathrm{C}$

c

c Lawrence Hutchings

c Hazard Mitigation Center

c University of California

c Lawrence Livermore Natinal Laboratory

C This work was produced at the University of California, Lawrence C Livermore National Laboratory (UC LLNL) under contract no.

W-7405-ENG-48 (Contract 48) between the U.S. Department of Energy (DOE) and The Regents of the University of California (University) for the operation of UC LLNL. The rights of the Federal Government are reserved under Contract 48 subject to the restrictions agreed upon by the DOE and University as allowed under DOE Acquisition Letter 97-1.

C DISCLAIMER

C This work was prepared as an account of work sponsored by an agency c of the United States Government. Neither the United States Government c nor the University of California nor any of their employees, makes c any warranty, express or implied, or assumes any liability or

c responsibility for the accuracy, completeness, or usefulness of any c information, apparatus, product, or process disclosed, or represents $c$ that its use would not infringe privately-owned rights. Reference $c$ herein to any specific commercial products, process, or service by c trade name, trademark, manufacturer or otherwise does not necessarily c constitute or imply its endorsement, recommendation, or favoring by $c$ the United States Government or the University of California. The c views and opinions of authors expressed herein do not necessarily c state or reflect those of the United States Government or the c University of California, and shall not be used for advertising or $c$ product endorsement purposes.

\section{NOTIFICATION OF COMMERCIAL USE}

c Commercialization of this product is prohibited without notifying the c Department of Energy (DOE) or Lawrence Livermore National Laboratory c (LLNL).

\section{program NetMoment}

C

c

c fmin is lowest frequency we can resolve,

C fmax is the highest frequency parameter (maxdim=10000, maxstat $=500$, maxev=100)

parameter (tstrial $=0.05$, fetrial $=10.0$ )

c maxstat is three times the number of stations to allow for the three component common /sres/ nfmin, nfmax, smodel, resid, omega0, fc,tstar, fbeg, del,

*yarray

common /simul/ ttstar, ssmodel,ik, xarray, vss 
complex tzaz(maxdim), tzar(maxdim), tzat (maxdim)

character*120 path, alpha, pathname (maxev), region, nnsf

character $\star 20$ cname (3), evname (maxev), nnsf 1 , nnsf 2 , revname

character* 3 rdc, ans, ans1, ans 2 , jnt, decon, acomp, rec, nrmspc, wpth

character* 4 cspp, cspt, blank, asbb, asb

real ma, mb

dimension yarray (10000), smodel(10000), resid(10000)

dimension y (maxstat), ttstar (maxstat), xarray (maxstat, maxdim),

*yarrayz (maxdim), yarrayr (maxdim), yarrayt (maxdim), slat (maxstat),

*slon (maxstat), traz (maxdim), trar (maxdim), trat (maxdim), asb (maxstat),

* spt (maxev) , bdp (maxev) , bsv (maxev), bm (maxev) , ssmodel (maxstat, maxdim)

*, elat (maxev), elon (maxev), eh (maxev), bstr (maxev), amag (maxev),

* tral (maxdim), tra2 (maxdim) , tra3 (maxdim) , acomp (maxstat) , pp (maxstat),

*avagmo (maxstat) , bmo (maxev), bfc (maxev)

$c$ need pp(maxstat) here because pp has different dimensions in simulspec and spe data ans1, ans2/'yes', 'y'/

pi2 $=6.28318530717$

$\mathrm{pi}=\mathrm{pi} 2 / 2.0$

nrmspc $=$ 'no'

open $(12$, file $=$ ' NetMoment. out' $)$

stime $=10.0$

print*,'Do you want to deconvolve EGFs with a Brune source'

print*,'this is done after the moment calculation'

read $(5, *)$ decon

print *, 'are records in acceleration (ACC), velocity (VEL), or dis

*placement (DIS)'

read $(5, *)$ rec

if (rec.ne. 'ACC'. and.rec.ne. 'VEL' and.rec.ne.'DIS') go to 3

call regionall (region, apz, vsp, vpm, zm, q, ma, mb)

136 format $\left(/ /\right.$, ' input velocity model: $v p=1, f 4.2,{ }^{\prime}+{ }^{\prime}$,

* $\mathrm{f} 4.2$, ' $\mathrm{xH}$ '/, 'over half-space at ', f5.2, 'km depth, with velocity ',

* $\mp 5.2 /, ' Q$ used for attenuation correction: ', f6.1/,'moment calculat

*ed from ',f5.2,' of S-arrivals; Sh and Sv'/'low frequency limit of

* the spectra',f4.1/'high frequency limit for inversion ',f5.1/

*'high frequency limit for fit to long period spectra ', f5.1/

*'starting value for tstar ', f6.4//)

print*, 'file name for sources of Greens functions'

read $(5, *)$ nnsf

open $(10, f i l e=n n s f)$

print*, 'file name for stations used in calculations'

read $(5, *)$ nnsf

open $(11$, file=nnsf)

print *,' '

print *,'do you want joint inversion for $t *$, moment, and corner fr

*equency'

$\operatorname{read}(5, *)$ jnt

if (jnt.eq.ans1.or.jnt.eq.ans2) then

print *,'joint inversion for corner frequency, moment and tstar' print *, ' '

print*,' do you want long period spectra levels to be normalized' read $(5, *)$ nrmspc

if (nrmspc.eq.ans1.or.nrmspc.eq.ans2) then

write $(6,101)$

write $(12,101)$

101 format('spectra normalized to have same long period amplitude for

*simultaneous inversion: omegao*xarray/avagmo1') endif

else

print *,'inversion for moment, $f c$, and tstar for individual statio 
*ns'

endif

print $*, '$ '

print *', 'do you want a whole path Q correction, from regionall.f' read $(5, *)$ wpth

print *, ' '

print *, 'what is the low frequency limit of the spectra'

read $(5, *)$ fmin

print *,'

print *', 'what is the high frequency limit for fit to Brune model'

read $(5, *)$ fmax

print *,' '

print *,' what is the high frequency limit for fit to long period $s$

*pectra'

$\operatorname{read}(5, *) \operatorname{fmax} 1$

print *,' '

print *, 'Do you want to make a radiation correction for'

print *,'difference between source events and elements'

read $(5, *)$ rdc

write $(6,16)$

16 format (/,'Enter path for source event files')

read $(5, '(a 80) ')$ path

C

write $(6,136)$ vsp, apz, zm, vpm, q, stime,fmin, fmax, fmax 1 , tstrial

write $(12,136)$ vsp, apz, zm, vpm, q, stime, fmin, fmax, fmaxl, tstrial

if (rdc.eq.ans1.or.rdc.eq.ans2) then

if (bstr (ne).ne.0.0.or.bdp (ne).ne.0.0.or.bsv(ne).ne.0.0) then

print *,'radiation correction factor applied'

write $(12, *)$ 'radiation correction factor applied'

endif

else

print *,'radiation correction factor of 0.63 utilized'

write $(12, *)$ 'radiation correction factor of 0.63 utilized'

endif

if (rec.eq.'ACC') write $(6, *)$ 'records integrated twice'

if (rec.eq. 'VEL') write $(6, *)$ 'records integrated once'

if (rec.eq. 'DIS') write $(6, *)$ 'records are in displacement'

if (rec.eq. 'ACC') write $(12, *)$ 'records integrated twice'

if (rec.eq. 'VEL') write $(12, *)$ 'records integrated once'

if (rec.eq.'DIS') write $(12, *)$ 'records are in displacement'

do 100 , ne $=1$, maxev

read $(10, *$, end $=1000)$ evname (ne), blank, elat (ne), elon (ne), eh (ne),

*amag (ne), bmo (ne), bfc (ne), bstr (ne), bdp (ne), bsv(ne)

if (evname (ne).eq.' ') go to 100

201 format $(\mathrm{a} 20,1 \mathrm{x}, \mathrm{f} 9.4,1 \mathrm{x}, \mathrm{f} 10.4,1 \mathrm{x}, \mathrm{f5} .2,3 \mathrm{x}, \mathrm{f3} .1,1 \mathrm{x}, \mathrm{f6} .1,1 \mathrm{x}, \mathrm{f} 4.1,1 \mathrm{x}$,

*f6.1)

bdp1 $=\operatorname{bdp}($ ne $) *($ pi2/360.0)

bsv1 $=$ bsv $(n e) *($ pi2 $/ 360.0)$

bstr1 $1=$ bstr $($ ne $) *(p i 2 / 360.0)$

$\mathrm{vzp}=\mathrm{vsp}+\mathrm{eh}(\mathrm{ne}) * \mathrm{apz}$

if (eh(ne).gt.zm) vzp = vpm

$\mathrm{vzs}=\mathrm{vzp} / 1.76$

$\mathrm{vss}=\mathrm{vsp} / 1.76$

C 'handbook on Mechanical Properties of Rocks', V II, R.D. Lama and V.S. Vutukur

c Trans Tech Publications, 1978, p. 245

$\operatorname{den} 1=\operatorname{sqrt}((\mathrm{vsp}-0.35) / 1.88)$

den2 $=\operatorname{sqrt}((\mathrm{vzp}-0.35) / 1.88)$

C

$C$ amag can be either magnitude or moment $X 10 * \star 20$

$c$ conversion to moment 
$\mathrm{bmo}(\mathrm{ne})=\mathrm{bmo}(\mathrm{ne}) * 1 \cdot 0 \mathrm{e}+20$

C

C calculate moment from magnitude

$\mathrm{bm}(\mathrm{ne})=(10 . * *(\mathrm{ma} * \operatorname{amag}(\mathrm{ne})+\mathrm{mb})) * 1.0 \mathrm{e}+20$

write $(6,106)$ evname (ne), elat (ne), elon(ne), eh (ne), amag (ne),

*bmo (ne), bfc (ne), bstr (ne), bdp (ne), bsv (ne)

write $(12,106)$ evname (ne), elat (ne), elon(ne), eh(ne), amag (ne),

*bm(ne), bfc (ne), bstr (ne), bdp (ne), bsv (ne)

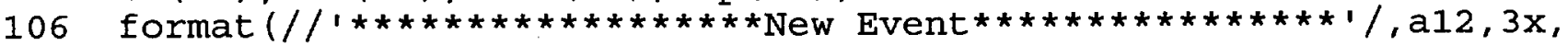

$\star f 7.4,2 x, f 9.4,2 x, f 5.2,1 x, f 3.1,1 x, e 12.4,1 x, f 4.1,2 x, f 4.0,3 x, f 3.0,2 x$,

*f5.0)

write $(6,103)$ den $1 * * 2$, den $2 * * 2$

write $(12,103)$ den $1 * * 2$, den $2 * * 2$

103 format ('surface density ',f4.2,' density at depth ',f5.2)

lentemp1 = indexb (path)

lentemp2 = indexb (evname (ne))

pathname $($ ne $)=\operatorname{path}(1:$ lentemp 1$) / / 1 / 1 /$ evname $($ ne $)(1:$ lentemp 2$) / / 1 / 1$

lentemp $3=$ indexb (pathname (ne) )

$i \mathrm{k}=0$

avagspec $=0.0$

avagmofft $=0.0$

amonet $=0.0$

avagfc $=0.0$

jstat $=0$

do $50 \mathrm{j}=1$, maxstat

avagmo $(j)=0.0$

read $(11, *$, end $=51)$ asbb, slatt, slonn, cname

if (asbb.eq.' ') go to 51

if (slatt.eq.0.0.or.slonn.eq.0.0) then

print *,'need station information'

go to 50

endif

if (cname (1) .ne.' .z' and.cname (1).ne.'.zzz'.and.cname (1) .ne.'.vz'.

*and. cname (1).ne.' .v.sun') then

write $(6,203)$ asbb

write $(12,203)$ asbb

203 format ('Station ',a4,' doesnt have first component at vertical')

go to 50

endif

$i k=i k+1$

asb $(i k)=a s b b$

do $4 \mathrm{ji}=1$, maxdim

$\operatorname{traz}(j i)=0.0$

$\operatorname{trar}(j i)=0.0$

$\operatorname{trat}(j i)=0.0$

$\operatorname{tzaz}(j i)=\operatorname{cmplx}(0.0,0.0)$

$\operatorname{tzar}(j i)=\operatorname{cmplx}(0.0,0.0)$

tzat $(j i)=\operatorname{cmpl} \times(0.0,0.0)$

$\operatorname{xarray}(i k, j i)=0.0$

$\operatorname{yarray}(j i)=0.0$

$\operatorname{yarrayz}(j i)=0.0$

yarrayr $(j i)=0.0$

4

yarrayt $(j i)=0.0$

cspt $=1,1$

sptt $=0.0$

lentemp4 = indexb (asbb)

nnsf = pathname (ne) $(1:$ lentemp3)//asbb $(1:$ lentemp4 $) / /$ cname $(1)$

call rsacl (nnsf, traz, np, timo, dt, maxdim, nerr)

if (nerr. ne. 0) then

$i k=i k-1$ 
call getfhv('T1', sptt, nerr)

if (nerr.eq. 0) cspt = ' $\mathrm{xx}$ '

nnsf = pathname (ne) $(1:$ lentemp 3$) / /$ asbb $(1:$ lentemp4 $) / /$ cname (2)

call rsacl (nnsf, trar, np, timo, dt, maxdim, nerr)

if (nerr ne. 0) then

$i k=i k-1$

go to 50

endif

if (cspt. ne. ' $\mathrm{xx}$ ') then

sptt $=0.0$

call getfhv('T1', sptt, nerr)

endif

if (nerr eq. 0) $\mathrm{cspt}={ }^{\prime} \mathrm{xx}{ }^{\prime}$

call getfhv ('CMPAZ', rot1, nerr)

if (nerr.ne.0) then

endif

if (cname (2).eq.'.n') rot $1=0.0$

if (cname $\left.(2) . e q . ' . e^{\prime}\right) \operatorname{rot} 1=90.0$

nnsf = pathname (ne) $(1:$ lentemp3)//asbb $(1:$ lentemp4)//cname (3)

call rsacl (nnsf, trat, np, timo, dt, maxdim, nerr)

if (nerr. ne. 0) then

$i k=i k-1$

go to 50

endif

if (cspt .ne. ' $x x^{\prime}$ ) then

sptt $=0.0$

call getfhv('TI', sptt, nerr)

endif

if (nerr .eq. 0) cspt $=$ ' $\mathrm{xx}$ '

call getfhv('CMPAZ', rot2, nerr)

if (nerr.ne.0) then

if (cname (3).eq.'.n') rot $2=0.0$

endif

if (cname (3).eq.'.e') $\operatorname{rot} 2=90.0$

if (ik.ne.1.and.dt.ne.dtlast) then

print *,'all seismograms need to have the same sampling rate'

stop

endif

dtlast $=d t$

jstat $=$ jstat +1

$\operatorname{spt}(j$ stat $)=\operatorname{sptt}$

slat (jstat) = slatt

slon (jstat) $=$ slonn

nnsf $1=\operatorname{asbb}(1:$ lentemp4) $/ /$ cname $(2)$

nnsf2 $=\operatorname{asbb}(1:$ lentemp 4$) / /$ cname $(3)$

call disazm(azm, azinv, dis, hdis, elat (ne), elon(ne), eh(ne),

*slat (jstat), slon (jstat))

write $(12,147)$ asbb, slatt, slonn, hdis, nnsfl, rot1, nnsf 2, rot 2

write $(6,147)$ asbb, slatt, slonn, hdis, nnsf $1, \operatorname{rot} 1, \operatorname{nnsf} 2, \operatorname{rot} 2$

147 format (/1***station ', a4,f8.4,f11.4,' distance $=1, \mathrm{f} 6.2 /$,' instrume *nt orientation for up on traces: '/, 'traz UP'/,'trar=', a6,' N', f4.0

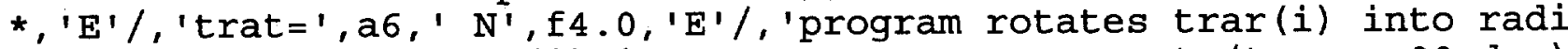
*al component and trat(i) into transverse component (trar +90 deg)

$\mathrm{C}$ *1)

c rotate records into radial and transverse motions do $200 \mathrm{jj}=1, \mathrm{np}$

$\operatorname{trarr}=\operatorname{trar}(j j) * \cos ((\operatorname{rot} 1-\operatorname{azm}) \star \operatorname{pi2} / 360)+$. 


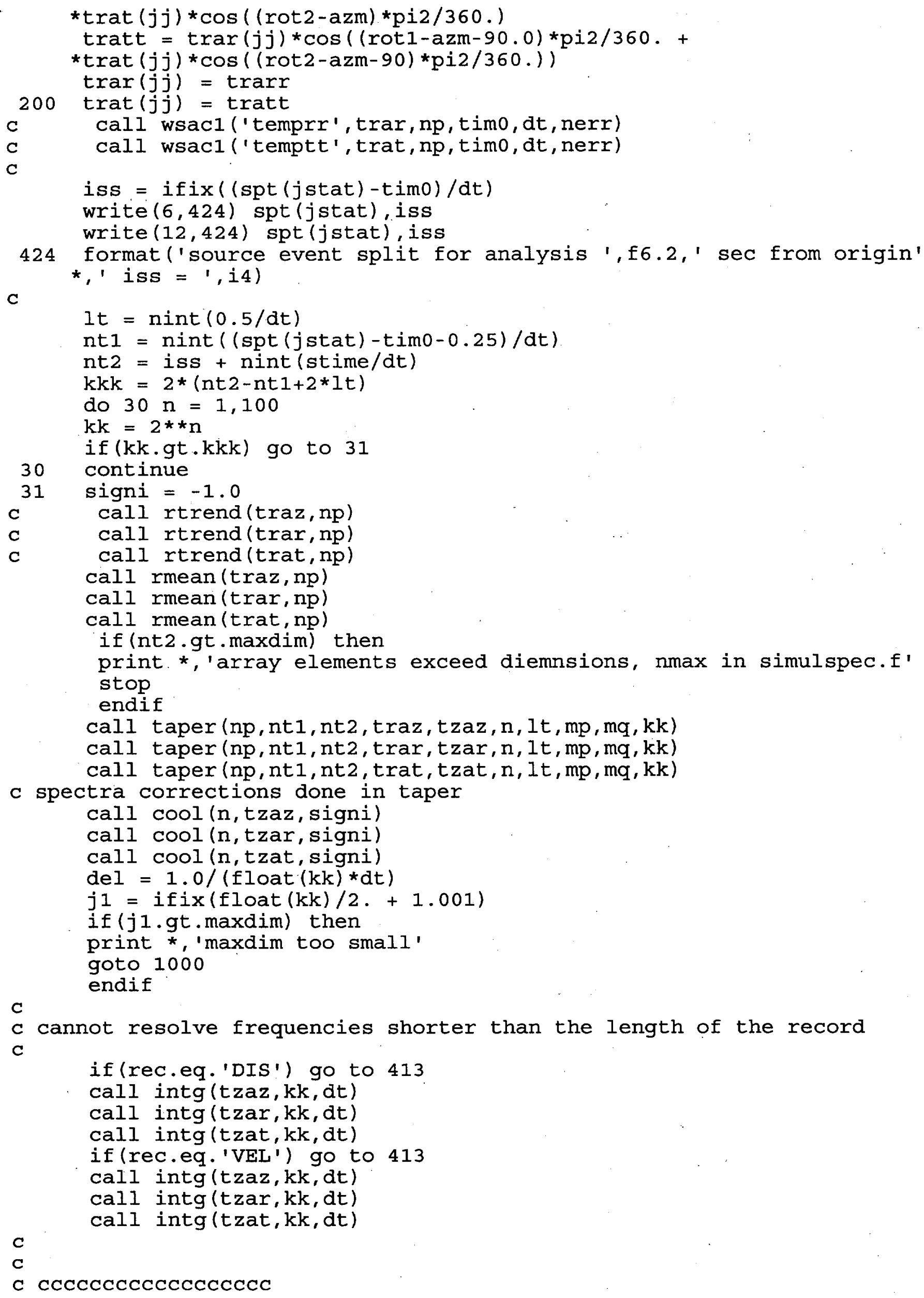


C

413 call linvel (eh(ne), dis, rp, angi, ainp, apz, vsp, vpm, zm, tt)

bzmm = azm - bstr (ne)

bzm1 $=$ bzmm* $($ pi2 $/ 360.0)$

aangi $=360 . *$ angi $/ \mathrm{pi} 2$

aainp $=360 . *$ ainp $/$ pi2

$\operatorname{ains} 1=\sin (\operatorname{ainp}) / 1.76$

$c$ roundoff accuracy

if (ainsl.gt.1.0.and.ains1.1t.1.05) ains $1=1.0$

ains $=\operatorname{asin}(\operatorname{ains} 1)$

$\mathrm{vss}=\mathrm{vsp} / 1.76$

aains $=360 *$ ains $/$ pi2

C

$\mathrm{ffsv}=\sin (\mathrm{bsv} 1) * \cos (2 . * \mathrm{bdp} 1) * \cos (2 . * \operatorname{ang} i) * \sin (\mathrm{bzm} 1)-\cos (\mathrm{bsv} 1)$

$\star \star \cos ($ bdp 1$) * \cos (2 . *$ angi $) * \cos ($ bzm 1$)+.5 * \cos ($ bsv 1$) * \sin ($ bdp 1$) *$

$* \sin (2 . * a n g i) * \sin (2 . * \mathrm{bzml})-.5 * \sin (\mathrm{bsv} 1) * \sin (2 . * \mathrm{bdp} 1) *$

$\star \sin (2 . * \operatorname{ang} i *(1 .+\sin (b z m 1) * \star 2))$

if (ffsv.lt.0.. and.ffsv.gt. -.25 ) ffsv $=-.25$

if (ffsv.ge.0..and.ffsv.It..25) ffsv $=.25$

if (rdc.ne.ans1.and.rdc.ne.ans2) ffsv $=0.63$

if (bstr1.eq.0.0.and.bdp1.eq.0.0.and.bsv1.eq.0.0) ffsv $=0.63$

C

$\mathrm{ffsh}=\cos (\mathrm{bsv} 1) * \cos (\mathrm{bdp} 1) * \cos (\mathrm{angi}) * \sin (\mathrm{bzm} 1)+$

* $\cos ($ bsv 1$) * \sin ($ bdp 1$) * \sin (\operatorname{angi}) * \cos (2 . *$ bzm 1$)+\sin (b \operatorname{sv} 1) * \cos (2 . * b d p 1)$

$\star \star \cos (a n g i) * \cos ($ bzm1 $)-.5 * \sin ($ bsv 1$) * \sin (2 . * b d p 1) * \sin ($ angi $) *$

$\star \sin (2 . * \operatorname{bzm} 1)$

if (ffsh.1t.0..and.ffsh.gt.-.25) ffsh $=-.25$

if (ffsh.ge.0..and.ffsh.lt..25) ffsh $=.25$

if (rdc.ne.ansl.and.rdc.ne.ans2) $\mathrm{ffsh}=0.63$

if (bstr1.eq.0.0.and.bdp1.eq.0.0.and.bsv1.eq.0.0) $\mathrm{ffsh}=0.63$

C

write $(6,311$ ) bzmm, bdp (ne), bsv(ne), aangi, aains, ffsv, ffsh

write $(12,311$ ) bzmm, bdp (ne), bsv(ne), aangi, aains, ffsv, ffsh

311 slip vector
takeoff angle',

format ('fault-stat azi

dip

* $\mathrm{s}$ incid angles $/ /, 6 \mathrm{x}, \mathrm{f} 6.1,5 \mathrm{x}, \mathrm{f4} .1,4 \mathrm{x}, \mathrm{f} 6.1,13 \mathrm{x}, \mathrm{f} 5.1,12 \mathrm{x}$,

* 4.1 /'radiation factors sv sh',

$* /, 24 x, f 6.3,3 x, f 6.3)$

C

c scale spectrum to get moment calculation: radiation, distance, free surface co

$c$ and moment factors

c

C free surface correction

C Aki and Richards p. 190

C

c p correction

C

ampp $1=\left(1 . /\right.$ vss $\left.* \star 2-2 \cdot{ }^{*} r p * * 2\right)$

ampp2 $=4 . * r p * * 2 * \cos ($ ainp) $* \cos ($ ains) $/($ vsp $* v s s)$

aampp $=($ ampp $1 * * 2+$ ampp 2$) * v s s * * 2 * v s p /(-2 . * v s p * \cos ($ ainp $) * a m p p 1)$

$c$ left hand coordinate

aampp $=-$ aampp

C

C

sv correction

aamsv $=(\operatorname{ampp} 1 * * 2+\operatorname{ampp} 2) * v s s * * 2 /(2 . * \cos (\operatorname{ains}) * \operatorname{ampp} 1)$

C

C sh correction

aamsh $=.5$ 
'C

c exclude factor of $10 * * 20$

facmor $=\operatorname{abs}\left(\right.$ hdis aamsv $^{*} 4 .{ }^{*} \mathrm{pi}$ *den $\left.1 * \operatorname{den} 2 * \mathrm{vss} * 2.5 * \operatorname{sqrt}(\mathrm{vzs}) / \mathrm{ffsv}\right)$

facmot $=\operatorname{abs}\left(\right.$ hdis $*$ aamsh $* 4 .{ }^{*} \mathrm{p} i * \operatorname{den} 1 * \operatorname{den} 2 *$ vss $\left.* 2.5 * \operatorname{sqrt}(\mathrm{vzs}) / \mathrm{ffsh}\right)$

C

do. $120 \mathrm{k}=1, \mathrm{j} 1$

ws $=$ float $(\mathrm{k}-1) * \mathrm{del}$

if (ws.eq.0.0) ws $=\mathrm{del}$

c undo correction for spectra from taper. $f$

$\operatorname{tzaz}(\mathrm{k})=\operatorname{tzaz}(\mathrm{k}) * \mathrm{float}(\mathrm{kk}) * \mathrm{dt}$

$\operatorname{tzar}(\mathrm{k})=\operatorname{tzar}(\mathrm{k}) * \mathrm{float}(\mathrm{kk}) * \mathrm{dt}$

tzat $(\mathrm{k})=$ tzat $(\mathrm{k}) *$ float $(\mathrm{kk}) * \mathrm{dt}$

$\operatorname{yarrayz}(\mathrm{k})=\operatorname{facmor} \operatorname{sqrt}(\operatorname{real}(\operatorname{tzaz}(\mathrm{k})) * \star 2+\operatorname{aimag}(\operatorname{tzaz}(\mathrm{k})) * * 2)$

yarrayr $(k)=$ facmor*sqrt $(\operatorname{real}(\operatorname{tzar}(k)) * * 2+\operatorname{aimag}(\operatorname{tzar}(k)) * * 2)$

$\operatorname{yarrayr}(\mathrm{k})=\operatorname{sqrt}(\operatorname{yarrayz}(\mathrm{k}) * \star 2+\operatorname{yarrayr}(\mathrm{k}) * \star 2)$

if (wpth.eq.ans1.or.wpth.eq.ans2)

C

*yarrayr $(\mathrm{k})=\operatorname{yarrayr}(\mathrm{k}) * \operatorname{cmplx}(\exp (\mathrm{pi} * w s * h d i s /(q * v z s)), 0.0)$

yarrayt $(k)=f a c m o t * \operatorname{sqrt}(\operatorname{real}(\operatorname{tzat}(k)) * * 2+\operatorname{aimag}(\operatorname{tzat}(k)) * * 2)$

if (wpth.eq.ans1.or.wpth.eq.ans2)

*yarrayt $(k)=\operatorname{yarrayt}(k) * \operatorname{cmplx}(\exp (p i * w s * h d i s /(q * v z s)), 0.0)$

c

$120 \operatorname{xarray}(i k, k)=\operatorname{sqrt}(\operatorname{yarrayr}(k) * * 2+\operatorname{yarrayt}(k) * * 2)$

C

C compute average spectral amplitudes from 1.0 to. $10.0 \mathrm{~Hz}$

$C$ make correction for tstar (Q)

C

alpha $=\operatorname{asbb}(1:$ lentemp4) $/ /$ '_Correspec_'//evname (ne) $(1:$ Ientemp2)//

$\star$ '.r'

call wsac1 (alpha, yarrayr, j1,0.0, del, nerr)

alpha $=$ asbb $(1:$ lentemp4) $/ /$ '_Correspec_'/evname (ne) $(1:$ lentemp2) $/ /$

*'.t'

call wsacl (alpha, yarrayt, j1,0.0, del, nerr)

C

$i 1=$ ifix $($ fmin * float $(\mathrm{kk}) * d t+1)$

i2 $=$ ifix $(\operatorname{fmax} 1 *$ float $(\mathrm{kk}) * d t+1)$

if (maxdim.1t.i2-i1+1) then

print $*, ' * \star * \star * \star \star$ maxdim too small $\star * \star \star \star \star * '$

go to 1000

endif

C

$\operatorname{aavg1}=0.0$

aavg2 $=0.0$

avagmo1 $=0.0$

do $15 i=i 1, i 2$

$\operatorname{aavg} 1=\operatorname{aavg} 1+\operatorname{yarrayr}(i)$

$\operatorname{aavg} 2=\operatorname{aavg} 2+$ yarrayt $(i)$

$15 \operatorname{avagmo1}=\operatorname{avagmo1}+\operatorname{xarray}(i k, i)$

$\operatorname{aavg1}=\operatorname{aavg1} / f l o a t(i 2-i 1+1)$

$\operatorname{aavg} 2=\operatorname{aavg} 2 /$ float $(i 2-i 1+1)$

avagmo1 = avagmol $/$ float $(i 2-i 1+1)$

c compute moment

C

\footnotetext{
avagmoo $=\operatorname{sqrt}(\operatorname{aavg} 1 * \star 2+\operatorname{aavg} 2 * \star 2)$
}

avagmoo $=$ avagmo $1 * 10.0 * * 20$

write $(6,317)$ avagmoo

write $(12,317)$ avagmoo

317 format (/'moment from spectral amplitudes: ' $\star, e 10.3$ ) 


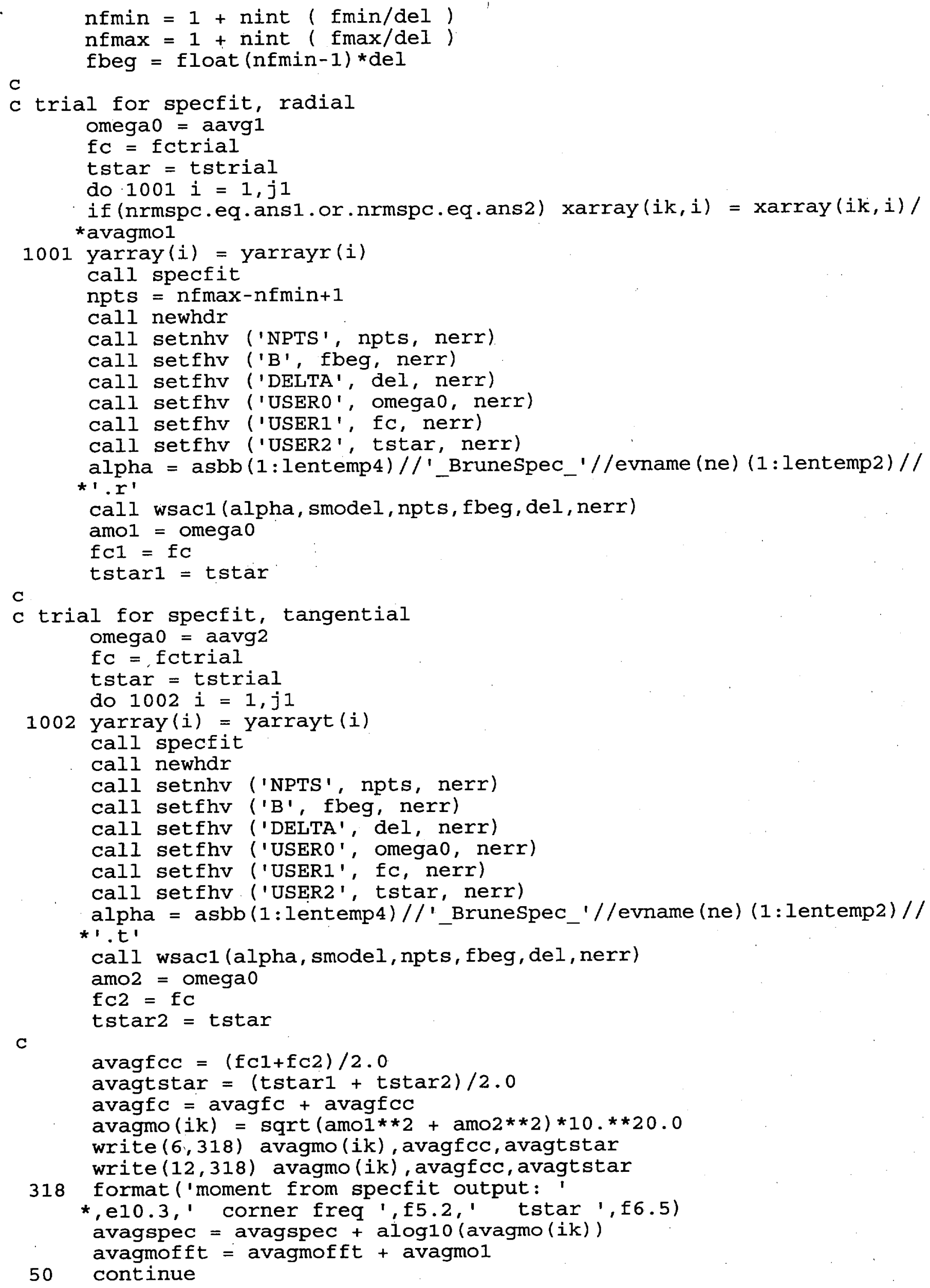


51 rewind (11)

avagspec $=10.0 * *($ avagspec $/$ float $(i k))$

avagmofft $=$ avagmofft/float $(i k)$

avagfc $=\operatorname{avagfc/float}(i k)$

if (ik.lt.2) go to 100

if $((i k+3) *(i k+2) \cdot g t$.maxstat $)$ then

write $(6,53)((i k+3) *(i k+2))$, maxstat

53 format (' $(i k+3) *(i k+2)=1, i 6, '$ maxstat $=1, i 5)$

print *,' maxstat too small'

go to 1000

endif

c trial for simulspec

$\mathrm{fc}=\operatorname{avagfc}$

omega 0 avagmofft

if (nrmspc.eq.ansl.or.nrmspc.eq.ans2) omega0 $=1.0$

tstar = tstrial

if (jnt.eq.ans1.or.jnt.eq.ans2) then

print $*, '$ '

print *,' call simulspec'

call simulspec (pp)

if (nrmspc.eq.ans1.or.nrmspc.eq.ans2) then

omega0 $=$ omega $0 *$ avagmofft

amonet $=$ omega $0 *(10 . * * 20.0)$

do $1004 j=1$, ik

do $1003 i=1, j 1$

$\operatorname{ssmodel}(j, i)=\operatorname{ssmodel}(j, i) *$ avagmofft

$1003 \operatorname{xarray}(j, i)=\operatorname{xarray}(j, i) * \operatorname{avagmofft}$

1004 continue

avagmofft $=\operatorname{avagmofft} * 10 . * * 20.0$

endif

C

C

Brune stress drop in kilobars, 1 bar $=10 * * 6$ dyne $/ \mathrm{cm}^{*} * 2$

str $=((7 . / 16)$.$* amonet *($ pi $2 * f c /(2.34 * \operatorname{vzs} * 10.0 * * 5)). * \star 3)$.

$\star 10.0 * *-3$.

do $150 \mathrm{k}=1$, ik

if (ttstar $(\mathrm{k}) .1 \mathrm{t} .00001)$ ttstar $(\mathrm{k})=.00001$

$\mathrm{asbb}=\mathrm{asb}(\mathrm{k})$

call newhdr

call setnhv ('NPTS', npts, nerr)

call setfhv ('B', fbeg, nerr)

call setfhv ('DELTA', del, nerr)

call setfhv ('USERO', omegao, nerr)

call setfhv ('USER1', fc, nerr)

call setfhv ('USER2', ttstar (k), nerr)

do $250 \mathrm{j}=1$, npts

$\operatorname{yarray}(j)=\operatorname{xarray}(k, j)$

250 smodel $(j)=\operatorname{ssmodel}(k, j)$

alpha $=\operatorname{asbb}(1:$ lentemp4) $/ /$ 'NetMoment_'//evname (ne) (1: lentemp2)

call wsacl (alpha, smodel, npt $\bar{s}$, fbeg, del, nerr)

alpha = asbb $(1:$ lentemp4 $) / /$ 'NetCorrec_'//evname (ne) $(1:$ lentemp2)

call wsac1 (alpha, yarray, npts, 0.0 , del, nerr)

150 continue

endif

varmo $=0.0$

c variance of mean is $1 / i k$ variance of population

c since differences are calculated in log space they are rations, so that

c results are a facotr. do $205 i=1$, ik

$205 \operatorname{varmo}=\operatorname{varmo}+(\operatorname{alog} 10(\operatorname{avagspec})-\operatorname{alog} 10(\operatorname{avagmo}(i))) * * 2$

varpop $=10 . * * \operatorname{sqrt}(\operatorname{varmo} /$ float $(i k-1))$ 


$$
\begin{aligned}
& \text { varmean = varpop/float }(\mathbf{i k}) \\
& \text { varmean }=\text { avagspec*varmean } \\
& \text { varpop = avagspec*varpop }
\end{aligned}
$$

write $(6,202$ ) evmame (ne), bmo (ne), bfc (ne), amag (ne), bm (ne), avagmofft,

*avagspec, avagfc, amonet, varmean, varpop, fc, (asb (i), ttstar (i),

*(1.0/(ttstar(i)*vss)), $i=1, i k)$

write $(12,202$ ) evname (ne), bmo(ne), bfc (ne), amag (ne), bm(ne), avagmofft

*, avagspec, avagfc, amonet, varmean, varpop, fc, (asb (i), ttstar(i),

*(2.0/(ttstar (i)*vss)), $i=1, i k)$

202 format $(/ / 1 * * * *$ Network Moments $* * \star * * 1$, al2//, moment from sources fi *le :',el2.4,', corner freq:',f5.1/, 'magnitude: ',f 3.1, ', moment fr *om moment/mag rel:', e12.4/ Log-Normal Average from peaks of spectr

*al amplitudes: ', e10.3/, 'Log-Normal Average from individual specfi

*t runs:' , elo.3,' corner frequency ',f6.2/,' Simultaneous solution $f$

* or all components: ', e10.3,', variance of mean ',e10.3/, 'variance

* of population ', e10.3,' corner frequency ',f6.2/'station tstar

* $Q(\mathrm{R}=2.0 \mathrm{~km}) 1 /,(2 \mathrm{x}, \mathrm{a} 4,5 \mathrm{x}, \mathrm{f} 6.4,4 \mathrm{x}, \mathrm{f} 7.0))$

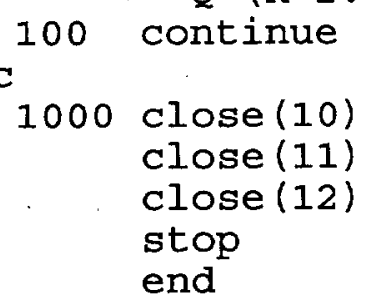

